\title{
Mathematical modeling of pigment dispersion taking into account the full agglomerate particle size distribution
}

\section{Kiil, Søren}

Published in:

Journal of Coatings Technology and Research

Link to article, DOI:

10.1007/s11998-016-9831-3

Publication date:

2017

Document Version

Peer reviewed version

Link back to DTU Orbit

Citation (APA):

Kiil, S. (2017). Mathematical modeling of pigment dispersion taking into account the full agglomerate particle size distribution. Journal of Coatings Technology and Research, 14(1), 69-84. https://doi.org/10.1007/s11998016-9831-3

\section{General rights}

Copyright and moral rights for the publications made accessible in the public portal are retained by the authors and/or other copyright owners and it is a condition of accessing publications that users recognise and abide by the legal requirements associated with these rights.

- Users may download and print one copy of any publication from the public portal for the purpose of private study or research.

- You may not further distribute the material or use it for any profit-making activity or commercial gain

- You may freely distribute the URL identifying the publication in the public portal

If you believe that this document breaches copyright please contact us providing details, and we will remove access to the work immediately and investigate your claim. 


\title{
Mathematical modelling of pigment dispersion taking into account the full agglomerate particle size distribution
}

\author{
Søren Kiil ${ }^{1}$ \\ Department of Chemical and Biochemical Engineering, Technical University of Denmark, \\ DTU, Building 229, DK-2800 Kgs. Lyngby, Denmark
}

\begin{abstract}
The purpose of this work was to develop a mathematical model that can quantify the dispersion of pigments, with a focus on the mechanical breakage of pigment agglomerates. The underlying physical mechanism was assumed to be surface erosion of spherical pigment agglomerates. The full agglomerate particle size distribution was simulated. Data from two previous experimental investigations were used for model validation. The first concerns two different yellow organic pigments dispersed in nitrocellulose/ethanol vehicles in a ball mill and the second a red organic pigment dispersed in a solvent-based acrylic vehicle in a three-roll mill. When the linear rate of agglomerate surface erosion was taken to be proportional to the external agglomerate surface area, simulations of the volume-moment mean diameter over time were in good quantitative agreement with experimental data for all three pigments. The only adjustable parameter used was an apparent rate constant for the linear agglomerate erosion rate. Model simulations, at selected values of time, for the full agglomerate particle size distribution were in good qualitative agreement with measured values. A quantitative match of the experimental particle size distributions could be obtained using time-dependent fragment distributions, but this resulted in a very slight improvement in the simulated transient mean diameter only. The model provides a mechanistic understanding of the agglomerate breakage process that can be used e.g. in the development of novel dispersion principles and for analysis of dispersion failures. The general applicability of the model, beyond the three pigments considered, needs to be confirmed.
\end{abstract}

\footnotetext{
${ }^{1}$ Corresponding author. Email: sk@kt.dtu.dk.
} 


\section{Nomenclature}

a

$\mathrm{C}_{\mathrm{P}}$

$\mathrm{d} / \mathrm{l}$

$\mathrm{d}_{\mathrm{c}, \mathrm{j}}$

$\mathrm{d}_{\mathrm{VM}}$

$\mathrm{d}_{\mathrm{p}}$

$\mathrm{d}_{\mathrm{p}, \mathrm{j}}$

$\mathrm{d}_{\mathrm{pm}, \mathrm{j}}$

$\mathrm{d}_{\mathrm{p}, \min }$

$\mathrm{d}_{\mathrm{p}, \max }$

$\mathrm{d}_{\mathrm{v} 90}$

$\mathrm{d}_{\mathrm{v} 99}$

$\mathrm{D}[4,3] \quad$ volume-moment mean diameter (eq 9), $\mathrm{m}$

$\mathrm{f}_{\mathrm{j} 0}$

$F\left(d_{p, j}\right) \quad$ cumulative fragment PSD up to $d_{p, j}$

$\mathrm{k}_{\mathrm{d}}$

$\mathrm{L}$

M

n

2, or 3)

$\mathrm{n}_{\mathrm{RR}}$

$\mathrm{N}_{\mathrm{j}}$

$\mathrm{N}_{\mathrm{j} 0}$

bers $/\left(\mathrm{m}^{3}\right)$

PSD

$R_{j}$

volume-moment mean diameter (eq 9), m

spherical agglomerate diameter, $\mathrm{m}$

erosion rate constant, $\mathrm{m}^{1-\mathrm{n}} \mathrm{s}^{-1}$

number of data points (eq 12)

number of discretization points

particle size distribution

volumetric rate of surface erosion, $\mathrm{m}^{3}$ pigment/s empirical parameter in eq (13)

solids concentration in mill base, $\mathrm{kg}$ pigment $/\left(\mathrm{m}^{3}\right.$ mill base $)$

diameter/length ratio of primary pigment particles

characteristic spherical agglomerate diameter for particle class $\mathrm{j}, \mathrm{m}$

diameter of spherical agglomerate in particle class $\mathrm{j}, \mathrm{m}$

arithmetic mean diameter of particle class j (eq 10), $\mathrm{m}$

spherical diameter of smallest agglomerate considered, $\mathrm{m}$

spherical diameter of largest agglomerate in distribution, $\mathrm{m}$

diameter, below which 90 percent of the volume distribution lies, $\mathrm{m}$

diameter, below which 99 percent of the volume distribution lies, m

dependency (exponent) of linear erosion rate on agglomerate diameter $(n=0,1$,

empirical dimensionless width constant in cumulative Weibull distribution number of agglomerates of size $\mathrm{d}_{\mathrm{p}, \mathrm{j}}$ per unit mill base volume, numbers $/\left(\mathrm{m}^{3}\right)$ initial number of agglomerates of size $d_{p, j}$ per unit mill base volume, num- 
$\mathrm{t}$

$t_{c}$

V

$\mathrm{V}_{\text {eff }}$

$\mathrm{V}_{\mathrm{j}}$

$\mathrm{V}_{\mathrm{L}}$

\section{Greek}

$\alpha$

$\varepsilon$

$\varepsilon_{\mathrm{A}}$

Ppigment

dispersion time, $\mathrm{s}$

"critical time" (10 hours) in multiple-parameter model, s

agglomerate particle volume, $\mathrm{m}^{3}$

effective mill base volume in which agglomerates are stressed, $\mathrm{m}^{3}$

agglomerate particle volume of size fraction $\mathrm{j}, \mathrm{m}^{3}$

total mill base volume, $\mathrm{m}^{3}$

\section{Introduction}

When pigments are manufactured, the targeted particle size distribution (PSD) will reflect the best compromise of particle properties. However, the individual particles will typically, due to van der Waals forces (i.e. physical interactions) and despite various surface treatments, be present in porous agglomerates in the final pigment powder. During subsequent coating or ink production, the agglomerates need to be taken apart to smaller entities in an attempt to optimize coating properties such as color strength and shade, opacity and hiding power, UV radiation resistance, gloss, and rheology. This process is called "dispersion" and is one of the most important steps in the production of pigmented coatings or inks. Dispersion is done with a socalled "mill base" (where no particles are actually "milled"), which consists of pigment powders in one or more viscous binder components, often also including dispersion agents and some solvent ${ }^{1}$. The dispersion obtained is subsequently mixed with other ingredients to form the final coating. 
The dispersion process itself is complex and consists of three separate steps: wetting of pigment surfaces, mechanical disruption (breakage) of agglomerates, and stabilization of the primary particles (or smaller agglomerates) formed, to prevent reagglomeration ${ }^{1}$. From a practical point of view, pigment dispersion must be an efficient process. This means that machine power consumption should be minimized and/or dispersion time kept as low as possible. Which type of equipment to use depends on the pigments of interest (agglomerate strength) and typically coating companies will have more than one apparatus type available in house. Classical dispersion equipment, such as bead, ball, and pearl mills, high speed impellers, and roller mills are still extensively used ${ }^{1}$, but also equipment based on new principles of dispersion have been introduced. Vacuum feeding of pigment powders (to remove air in agglomerates), breaking of large agglomerates with mechanical forces under dry conditions, and subsequent fast contact between agglomerates and wetting liquid under pressure are examples in this direction ${ }^{2}$. Also, so-called rotor-stator principles are used, where high shear forces are generated in a workhead or a narrow gap ga $^{3,4}$.

Due to commonly lower particle size and more problematic wetting, organic pigments are frequently more difficult to disperse compared to inorganic pigments. Organic pigments are expensive and it is mandatory that they are thoroughly dispersed. Poor agglomeration may result in a 30 to $50 \%$ reduction in tinting strength ${ }^{1}$.

In practice, the coatings manufacturer usually considers dispersion to be related to the number of oversized particles detected on a fineness of grind gauge (grindometer). However, this simple, but practically very useful, technique gives only an indication of particles (agglomerates) whose dimensions are about $10 \mu \mathrm{m}$ or greater ${ }^{5,6}$. While these high particle sizes can cause film surface defects, and therefore should be reduced, the grind gauge does not give information on how the average particle size develops, which is of relevance for many coating properties $^{7}$. It is, in many ways, more informative and reliable to also work with the entire agglomerate PSD or at least an average particle size based on the full PSD. Such measurements are in many cases now possible using modern laser diffraction equipment and if dilution of 
the sample, prior to a measurement, can be done directly in the relevant binder liquids, very useful data sets can be obtained (see e.g. McGarvey et al. ${ }^{8}$ ). To supplement PSD measurements, mechanistic mathematical models, describing the dispersion process, can help to provide a solid understanding of the influencing process parameters and the kinetics of dispersion. The latter is important, for instance, when evaluating when to stop a dispersion process to avoid an inefficient continuation. With mathematical models available (and "calibrated"), it is also easier to find the reasons for possible dispersion failures on a case to case basis in a structured manner and subsequently in a fast way find solutions to the problems encountered ${ }^{1}$. Detailed models also provide mechanistic information in a formalized way that may be used in the design and development of novel dispersion equipment.

\section{Previous mathematical models and purpose of present work}

Despite the huge importance of dispersion in the fields of inks and coatings, attempts at quantitative descriptions of the process in relevant equipment are very few ${ }^{1}$. However, a number of comprehensive mathematical models have been developed for dispersion of fillers in molten plastics (composites) using high shear devices such as extruders. Starting with the coatings area, Wahl et al. ${ }^{7}$ derived a one-parameter model for how the number of "large-size" agglomerates develop over time in a high speed disperser. Agglomerates were assumed to have the same "tendency to disperse" and model predictions were compared to grindometer readings. Winkler et al. ${ }^{9}$ set up a model for pigment dispersion based on a probabilistic approach. Using expressions developed for breaking and stress probabilities, the total probability of an agglomerate being dispersed could be calculated. An important finding was that a lack of energy density cannot be compensated by dispersing for a longer time. The model is useful for an empirical evaluation of the overall dispersion process, but does not explicitly include the size of agglomerates and no specific dispersion mechanism is considered.

Bohin et al. ${ }^{10}$ studied the single particle kinetics of dispersion of high-porosity silica agglomerates in silicone polymers. Initial agglomerate size was in the $\mathrm{mm}$ range and experiments 
took place in a rotating cone and plate device. The rate of erosion was assumed to be proportional to the excess of the hydrodynamic force acting on an agglomerate relative to its cohesive strength. A strong dependency of the erosion rate on the silicone infiltration rate and shear rate used was found. Similar effects of porosity and infiltration rates were found by Lee et al. ${ }^{11}$ for $\mathrm{TiO}_{2}$ agglomerates (mm size) in PDMS fluids at rather low shear rates. In this case, the agglomerate porosity needed to exceed $65 \%$ for the infiltration rate to influence the dispersion rate.

Lozano et al. ${ }^{12}$ set up a model to predict the agglomerate size distribution of $\mathrm{CaCO}_{3}$ agglomerates being dispersed in polypropylene in a twin-screw extruder. The model includes a rupture and an erosion mechanism and was validated against axial PSD extruder data obtained from micrographs of polished samples. In total, the model contains four adjustable parameters for the rupture kinetics (in practice the splitting fractions into the six discrete particle classes considered in the experimental data), three adjustable erosion rate constants, and a weight factor (taken to 50\%) indicating the importance of each mechanism. The three erosion parameters were estimated from a separate experiment with a selected mixer.

Lee et al. ${ }^{13}$ modelled a bead mill process for dispersion of coagulated nanoparticles into coolant-oil. A population balance was used to predict the average particle size over time based on an assumption of a dominant two-piece rupture mechanism (erosion was not considered). Three adjustable parameters, with values fitted using a reduced set of data, were needed in the model. Simulations with the adjusted parameters gave prediction results that "reasonably matched" the rest of the experimental data.

Potente et al. ${ }^{14}$ simulated dispersion of fillers in molten polymers using co-rotating twin-screw extruders. Erosion, rupture, and clustering mechanisms were all included with explicit theoretical expressions (derived in Flecke et al. ${ }^{15}$ ) for the rates of each phenomenon. The temporal derivative of the average agglomerate diameter was first order in the average agglomerate diameter for all three mechanisms. For the erosion mechanism, active already at low shear rates, primary particles only were assumed to erode from the surface. The rupture mechanism sets 
in at a critical shear rate and at high shear rates, the two mechanisms take place in parallel. Experimentally, a PSD was estimated, using image analysis, for $\mathrm{CaCO}_{3}$ and talc particles in three polymers in an extruder. The particle median was compared with simulations and a good qualitative agreement was found.

Finally, Baldyga et al. ${ }^{16,17}$ considered dispersion of nanoparticle clusters (fumed aerosol) in a polymethylsiloxane liquid in a rotor-stator mixer. Their very detailed particle structure model (including fractal geometries and various structure parameters) was combined with computational fluid dynamic calculations describing the flow conditions and the "trends" of a very narrow bi-modal PSD could be predicted.

Summarizing the above analysis, it can be concluded that detailed studies have been conducted on single mm-size agglomerates and on models for dispersion processes, mainly in extruders. The models typically involve tuning of a number of adjustable parameters by comparison with measured average diameters. In the coatings field, very few modelling studies are available. In his recent book on dispersion of pigments and fillers, Winkler ${ }^{1}$ states that the dispersion process "is still often looked upon as being more of an art than a fundamental, scientifically underlain technical process" and that "quantitative prognoses are difficult".

The purpose of the present work is to develop a mathematical model that, based on a mechanistic understanding, quantifies the dispersion of pigments (or more precisely, the mechanical breakage of agglomerates), while taking into account the entire agglomerate PSD. An important requirement of this engineering model is that it should be sufficiently simple to allow daily use on dispersion processes (i.e. the number of adjustable parameters should be low and have a physical meaning). Simulations with the model are compared to previous experimental investigations of dispersion processes with selected organic pigments. Based on the analysis conducted, future experimental studies, needed to advance the field, will be suggested. 


\section{Mathematical modelling}

A mathematical model capable of simulating dispersion of pigment agglomerates is described here. Only liquid dispersion, of relevance for coatings and inks, is considered. The underlying mechanism is illustrated in Fig. 1. In actual coating systems, the dispersion process is always incomplete in that the pigment is never entirely present as single discrete particles. As an example, Hornby and Murley ${ }^{18}$ estimated, for $\mathrm{TiO}_{2}$ pigments in an alkyd system and based on electron microscopy, that only about $30 \%$ of the pigment particles were present as single particles, the remainder being present as groups of two, three, or more. Brisson et al. ${ }^{5}$ found similar numbers.

\section{Model assumptions}

- The dispersion process is in batch mode (i.e. there are no input or output streams to the mill base).

- Only one pigment type at a time is present in the disperser (i.e. pigment mixtures are not considered).

- Agglomerates are made up of primary particles, held together by physical van der Waals forces. No aggregates, held together at crystal planes by chemical bonds, are present (as a rule of thumb, chemical bonds are about 10 times stronger than physical bonds $\left.^{1}\right)$.

- All pigment agglomerates and erosion fragments are spherical.

- Agglomerates decrease in size due to surface erosion only (i.e. rupture is considered negligible).

- Clustering of agglomerates or fragments of these (as suggested by Potente et al. ${ }^{14,19}$ for composites in extruders) and any potential reagglomeration are considered negligible.

- The agglomerates have a porosity sufficiently low to prevent dispersion being influenced by the rate of liquid (vehicle) penetration into pigment agglomerates ${ }^{11}$ (i.e. the 
penetration is instantaneous and mechanical breakage of agglomerates is the ratedetermining step in the overall dispersion process).

- Agglomerate fragments, originating from surface erosion, are displaced to smaller agglomerate sizes according to a cumulative Weibull distribution.

- Agglomerates cannot erode to a diameter smaller than a certain minimum size, $d_{p, m i n}$.

- The dispersion process is isothermal and solvent evaporation can be neglected.

The above assumptions call for some discussion and the most important ones are readdressed in a later paragraph. The mathematical model can now be developed.

\section{Population balance equation}

To keep track of the PSD of agglomerates, a conservation equation based on numbers is needed

$$
\text { accumulation }=\text { input }- \text { output }+ \text { net generation }
$$

There are no input and output streams because a batch process is considered. Expressed in quantitative terms, the population balance equation can now be written, in discrete form, as

$$
\frac{d N_{j}}{d t}=\frac{R_{j+1} N_{j+1} \alpha}{\left(V_{j+1}-V_{j}\right)}-\frac{R_{j} N_{j} \alpha}{\left(V_{j}-V_{j-1}\right)}+\sum_{k=j}^{M} \frac{\alpha R_{k} N_{k}\left(F\left(d_{p, j}\right)-F\left(d_{p, j-1}\right)\right)}{V_{j}}
$$

with initial condition

$$
N_{j}(t=0)=N_{j 0}
$$

where $\mathrm{j}=1, \ldots, \mathrm{M} . \mathrm{M}$ is the number of chosen discretization points in the particle interval $\left[\mathrm{d}_{\mathrm{p}, \min } ; \mathrm{d}_{\mathrm{p}, \max }\right] . \mathrm{N}_{\mathrm{j}}$ is the number of particles (agglomerates) per unit mill base volume in the volume size class $\left[\mathrm{V}_{\mathrm{j}-1} ; \mathrm{V}_{\mathrm{j}}\right]$. The derivation of an equation somewhat similar to eq (2), as well as an experimental verification, was done in Kiil et al. ${ }^{20}$ for dissolving limestone particles in an acidic mixed flow reactor and modified here to describe batch dispersion. The first and second generation term on the right of eq(2) accounts for the number of larger agglomerates, of size $d_{p, j+1}$, eroding to the current size, $d_{p, j}$, and particles of the current size eroding to size 
$d_{p, j-1}$, respectively. The last term on the right of eq (2) accounts for spherical erosion fragments entering the current size class from larger classes. In this last term, $F\left(d_{p, j}\right)$ represents a cumulative fragment PSD up to $d_{p, j}$. More details on the form of $F\left(d_{p, j}\right)$ are provided later. This approach means that the shrinking agglomerate cores and the erosion fragments produced are handled with separate terms in eq (2). The parameter $\alpha\left(=\mathrm{V}_{\text {eff }} / \mathrm{V}_{\mathrm{L}}\right)$ accounts for the fact that not all the dispersion liquid volume $\left(\mathrm{V}_{\mathrm{L}}\right)$ in a dispersion device may be active in dispersing the pigments (i.e. only $\mathrm{V}_{\text {eff }}$ is active) as discussed by Winkler et al. ${ }^{9}$ and Winkler ${ }^{1}$. When performing a simulation, $\mathrm{V}_{\mathrm{j}}$ and $\mathrm{d}_{\mathrm{p}, \mathrm{j}}$ values are specified initially, when selecting the number of discretization points, whereas $\mathrm{N}_{\mathrm{j}}$ values are calculated as a function of dispersion time.

\section{Volumetric rate of surface erosion}

The volumetric rate of surface erosion, $R_{j}$, needed in eq (2), can be expressed, via a differentiation, as

$$
R_{j}=-\frac{d\left(\frac{\pi}{6} d_{p, j}{ }^{3}\right)}{d t}=-\frac{\pi}{2} d_{p, j}{ }^{2} \frac{d\left(d_{p, j}\right)}{d t}
$$

where the linear agglomerate erosion rate, $\mathrm{d}\left(\mathrm{d}_{\mathrm{p}, \mathrm{j}}\right) / \mathrm{dt}$, is a potentially size-dependent erosion rate.

\section{Linear agglomerate erosion rate}

To solve the population balance, equation (2), a kinetic expression is needed for the linear agglomerate erosion rate, $\mathrm{d}\left(\mathrm{d}_{\mathrm{p}, \mathrm{j}}\right) / \mathrm{dt}$. It is assumed, in agreement with practical observations, that larger agglomerates in general erode faster than smaller agglomerates. Therefore, the rate of agglomerate surface erosion is assumed proportional to $\mathrm{d}_{\mathrm{p}, \mathrm{j}}{ }^{\mathrm{n}}$ and expressed as

$$
-\frac{d\left(d_{p, j}\right)}{d t}=k_{d} d_{p, j}^{n}
$$


where $d_{p, j}$ is the current agglomerate diameter, $k_{d}$ is a rate constant, and $n$ the rate order (equal to $0,1,2$, or 3$). \mathrm{k}_{\mathrm{d}}$ is a function of the type of pigment agglomerates (e.g. porosity, cohesion strength, and primary particle shape), vehicle and dispersion equipment considered, pigment concentration in the vehicle, presence of dispersing additives and moisture, as well as operation parameters selected for a given dispersion experiment. In the present work, these dependencies are not mapped, only the overall underlying mechanical dispersion mechanism is investigated and $k_{d}$ can be considered an "apparent" rate constant. The value of $n$ to use in eq (5) will be investigated in the Results and Discussion section.

\section{Initial agglomerate particle size distribution}

The initial number distribution is calculated from

$$
N_{j 0}=\frac{C_{P} f_{j 0}}{\rho_{\text {pigment }}\left(1-\varepsilon_{A}\right)\left(\frac{\pi}{6} d_{p, j}{ }^{3}\right)}
$$

where $f_{j 0}$ is the initial weight fraction of particles of size $d_{p, j}$ in the mill base. $C_{P}$ is the pigment concentration and $\varepsilon_{\mathrm{A}}$ is the agglomerate porosity. Note, that $\mathrm{N}_{\mathrm{j} 0}$ and $\mathrm{N}_{\mathrm{j}}$ are dependent on the values of $\mathrm{C}_{\mathrm{P}}, \rho_{\text {pigment }}$, and $\varepsilon_{\mathrm{A}}$, but not the PSDs presented later because these are by nature relative variables.

\section{Cumulative fragment distribution resulting from surface erosion of an agglomerate}

To describe the cumulative fragment PSD resulting from surface erosion, $F\left(d_{p, j}\right)$, the so-called cumulative Weibull distribution was used

$$
F\left(d_{p, j}\right)=1-\exp \left[-\left(\frac{d_{p, j}}{d_{c, j}}\right)^{n_{R R}}\right]
$$

where $n_{R R}$ is a constant describing the material uniformity ("uniformity constant") and $d_{c, j}$ is the "characteristic particle size", defined as the size at which $(1-1 / \mathrm{e})$ or $63.2 \%$ of the particles (by weight) are smaller ${ }^{21}$. It is assumed that $\mathrm{d}_{\mathrm{c}, \mathrm{j}}$ in all cases can be calculated from the arithmetric mean value 


$$
d_{c, j}=\frac{d_{p, j}+d_{p, \min }}{2}
$$

where $d_{p, m i n}$ is the smallest diameter considered in the analysis (i.e. either primary particle diameter or lowest experimentally detectable particle size). The Weibull (or the associated Rosin-Rammler) distribution has previously been used e.g. to describe the distribution resulting from crushing and milling ${ }^{21}$, as well as breakage of particles ${ }^{22}$ and was assumed valid here for describing the distribution of surface erosion fragments.

\section{Volume-moment mean diameter}

The mean diameter of a PSD can be represented in a number of ways ${ }^{23}$. It was chosen here to work with the volume-moment mean diameter (i.e. the mean of the volume distribution). Used on a PSD, the volume-moment mean diameter, $\mathrm{d}_{\mathrm{VM}}$, can be written $\mathrm{as}^{23}$

$$
d_{V M}=D[4,3]=\frac{\sum_{j=1}^{M} N_{j} d_{p, j}^{4}}{\sum_{j=1}^{M} N_{j} d_{p, j}^{3}}
$$

\section{Frequency distribution}

The frequency distribution is calculated as a model output and for an individual particle class, on a logarithmic particle axis, $\mathrm{dV} / \mathrm{d} \log \left(\mathrm{d}_{\mathrm{p}}\right)$, was calculated according to

$$
\left.\frac{d V}{d \log \left(d_{p}\right)}\right|_{d_{p m, j}}=\frac{F\left(d_{p, j}\right)-F\left(d_{p, j-1}\right)}{\log \left(d_{p, j}\right)-\log \left(d_{p, j-1}\right)}
$$

where $d_{p m, j}$ is the artithmetic mean diameter of particle class $j$.

\section{Closure of volume balance}

It is essential to investigate if the overall agglomerate volume balance can be closed (i.e. the total particle volume is constant) at all values of dispersing time during the simulations. The following equation was used for this purpose

$$
\left|\frac{\sum_{j=1}^{M} N_{j 0} d_{p, j}^{3}}{\sum_{j=1}^{M} N_{j} d_{p, j}^{3}}-1\right|<\varepsilon
$$


where $\mathrm{N}_{\mathrm{jo}}$ and $\mathrm{N}_{\mathrm{j}}$ are the number of particles of size $\mathrm{d}_{\mathrm{p}, \mathrm{j}}$ present initially $(\mathrm{t}=0)$ and at time $\mathrm{t}$ in a given size class, respectively. $\varepsilon$ is the accepted closure tolerance, specified here to $10^{-3}$.

\section{Dimensionless variables, estimation of parameters, and solution of the mathematical model}

The model was rendered dimensionless by introduction of suitable dimensionless variables for $\mathrm{N}_{\mathrm{j}}$, $\mathrm{t}$, and $\mathrm{d}_{\mathrm{p}, \mathrm{j}}$. Input parameters to the model are pigment loading, $\mathrm{C}_{\mathrm{P}}$, pigment density (skeletal), $\rho_{\text {pigment }}$, agglomerate porosity, $\varepsilon_{\mathrm{A}}$, the initial agglomerate PSD, the minimum agglomerate diameter (typically equivalent to the primary particle size), $d_{p, \min }$, the uniformity constant, $\mathrm{n}_{\mathrm{RR}}$, and the fraction of dispersing volume active in the dispersion liquid, $\alpha$. The latter parameter was arbitrarily taken to 0.5 . In the model, $\mathrm{k}_{\mathrm{d}}$ and $\alpha$ only appear as the product, $\mathrm{k}_{\mathrm{d}} \alpha$, and simulations are not affected by the value chosen for $\alpha$ (except that another $\mathrm{k}_{\mathrm{d}}$ value is obtained in the fitting process). The consequence of this is that the effect of $\mathrm{k}_{\mathrm{d}}$ and $\alpha$ cannot be separated and the $k_{d}$ values obtained are not "true" erosion rate constants. The value of $\alpha$ is expected to be system dependent.

The parameter $\mathrm{n}_{R R}$ in the Weibull distribution should be higher than 5 for $\mathrm{B} 3 \mathrm{~L}$ pigment (to be introduced later) to ensure the cumulative distribution of fragments, $F\left(d_{p, j}\right)$, reaches unity below the current size $d_{p, j}$ (agglomerates cannot grow in size). The model is not sensitive to $n_{R R}$ values above 5, but should also not be taken to very high values $(>30)$, where numerical instabilities can start to appear. For LBG and DPP pigments (also introduced later), the Weibull parameter $n_{R R}$ must be in the interval $15<n_{R R}<30$ and $20<n_{R R}<30$, respectively.

The geometrical dependency of the rate (i.e. the parameter $n$ ) needs to be selected and the model contains a single adjustable parameter, the surface erosion rate constant, $\mathrm{k}_{\mathrm{d}}$. Estimation of $\mathrm{k}_{\mathrm{d}}$ and $\mathrm{n}$ is discussed in the Results and Discussion section.

The coupled ordinary differential equations in the model (population balance equation) were solved using an available integration routine. To obtain convergence, it was necessary to work with at least 70 discretization points, resulting in an equal number of ordinary differential equations. The discretization points were selected based on an equal distribution of particle 
volume in each particle class. This means that the particle classes do not have the same width and the class selection process was handled using a vector searching software ${ }^{24}$ combined with linear interpolation on the discrete cumulative distribution $(\mathrm{t}=0)$ obtained from experimental data (see next paragraph). Calculation time, for the most demanding simulations, was less than one minute on the "standard" PC used.

\section{Experimental data for model validation}

Accurate experimental data of dispersion processes, taking into account the entire agglomerate particle distribution, and available in the open literature are very limited. However, very useful data have been published by McGarvej et al. ${ }^{8}$. They studied the dispersion of two CI Pigment Yellow 13 organic pigments (termed Yellow LBG and Yellow B3L) in a lowviscosity nitrocellulose/ethanol-based ink millbase. The pigments were dispersed in a ball mill, using balls of metal, whereby intensive shear is imparted to the pigment agglomerates when the balls roll over each other with a relatively thin layer of mill base between them. Dispersion time was 120 hours with water cooling. The agglomerate PSD was measured at regular intervals on a Malvern laser diffraction based apparatus, which gives as output a volume distribution referred to the equivalent spherical volume diameter. Data for refractive index of the pigments were used as input ${ }^{8}$. To avoid influencing the PSD during the measurement, the dilution medium for the measuring cell was the (low viscous) ink varnish itself. However, also ethanol was used as diluting medium and "the same trends" were observed. McGarvej et al. ${ }^{8}$ reported the frequency distributions as curves of volume percentage versus particle diameter only, without specifying the interval width. Consequently, to convert these data to a cumulative distribution, which is more convenient to work with in a simulation study, it was necessary to read about 75 data points from each of the curves in McGarvej et al. ${ }^{8}$, using a specialized image software. The experimental cumulative distribution, $F\left(d_{p, j}\right)$, was calculated from 


$$
F\left(d_{p, j}\right)=\frac{\sum_{i=1}^{j} V_{i}}{\sum_{k=1}^{L} V_{k}}
$$

where $L$ is the number of data points. The experimental volume-moment mean diameter, $d_{V M}$, was calculated using eq (9). It should be noted that the initial PSD (i.e. at $t=0$ ), was not provided in McGarvey et al. ${ }^{8}$. The first distribution was recorded after 1 hour of dispersion. The reason for this was not stated, but presumably "very large" agglomerates have been present initially, outside the measurement apparatus-allowed maximum diameter of $80 \mu \mathrm{m}^{8}$. This is the reason that the total dispersion time in the figures presented later runs up to 119 hours only (as opposed to 120 hours in the reference). The experimental PSD recorded after 1 hour was used as model input (initial distribution) corresponding to $t=0$. Experimental uncertainties (standard deviations) could not be obtained from the data in McGarvey et al. ${ }^{8}$, but for Malvern PSD measurements, the uncertainties are expected to be quite low when "correct" (particle compliant) dispersion liquid is used (as was done in McGarvey et al. ${ }^{8}$ ).

A third experimental series was taken from Van et al. ${ }^{25}$. They studied, amongst others, dispersion of Irgazin ${ }^{\mathrm{TM}}$ DPP red BO (PR 254) from Ciba Speciality Chemicals. The vehicle (for screen printing inks) used was a blend of a poly(methyl methacrylate) (PMMA) resin and a PMMA copolymer resin at a 3:5 solids ratio at $42.40 \mathrm{wt} \%$ total solids in EB acetate solvent. Dispersion took place in a three-roll mill. The cumulative distribution was obtained as explained above for the two yellow pigments.

\section{Results and discussion}

The purpose of the mathematical model, developed in the previous sections, is to provide a tool that can be used for analyzing the dispersion mechanism of pigment agglomerates. To verify the pigment dispersion model, three experimental series of data with organic pigments, where full particle size distributions were considered, have been used (see details in experimental section). 
In this experimental investigation, pigment dispersion in a ball mill was considered. Yellow 13 B3L pigment was used. Dispersion time was long, 119 hours in total, and full PSDs were presented at four values of time.

\section{Mean agglomerate size over time}

With the purpose of initially estimating adjustable model parameters, transient data for the mean agglomerate size was considered. Simulations and experimental data are compared in Fig. 2 (bottom plot). Both the dependency of the linear erosion rate on agglomerate diameter, $\mathrm{n}$, and the erosion rate constant, $\mathrm{k}_{\mathrm{d}}$, were varied in an attempt to obtain the best possible agreement. The exponent $n$ was varied only as $n=0,1,2,3$. The first case $(n=0)$, corresponds to a constant and identical linear erosion rate for all agglomerates, whereas $n=1,2,3$ corresponds to an agglomerate diameter-dependent, an external surface area-dependent, and a volume-dependent linear erosion rate, respectively. The erosion rate constant was allowed to vary freely. It can be seen in Fig. 2 (bottom plot) that $n=0$ and $n=1$ give simulations quite far from the experimental data. Initially, the simulated erosion rates are too slow, whereas at long dispersion times the rate of dispersion levels off with a lower mean agglomerate diameter in the simulations compared to experimental data. When $n=3$, the initial rate is somewhat too high and at long times the simulation converges to a mean agglomerate value higher than the experimental. Initially, when many large agglomerates are present, $\mathrm{n}=3$ will lead to a too high erosion rate, but as the agglomerates get smaller, the erosion rate will die out rapidly due to the high value of $n$. For $n=2$, the simulation (solid line) is in very good agreement with experimental data. It was assumed in the model that the dominating mechanism of dispersion is surface erosion and $n=2$ actually corresponds to an external surface area dependency of the rate. Contrary to this, Potente et al. ${ }^{19}$ suggest to use what corresponds to $\mathrm{n}=1$ (and $\mathrm{d}_{\mathrm{p}}$ a mean diameter) for dispersion of fillers $\left(\mathrm{CaCO}_{3}\right.$ and talc) in a twin-screw extruder. As explained in the introduction, the model of Potente et al. ${ }^{14,19}$ contains 8 adjustable parameters, only primary 
particles are assumed to erode from the agglomerate surface, and particle sizes below $37 \mu \mathrm{m}$ could not be taken into account by the image analysis technique used for model validation. It may therefore be hard to confirm their assumption of $n=1$.

\section{Full agglomerate particle size distributions at selected values of time}

The next issue to consider is how well the full PSDs are estimated when using $n=2$ and the associated value of $k_{d}$ from Fig. 2 (bottom plot). In Fig. 3 and 4, simulations (full lines) are compared to experimental data for four values of dispersion time (notice the logarithmic $\mathrm{x}$ axis). Starting with Fig. 3, representing "snapshots" after 5 and 15 hours of dispersion, respectively, it can be seen that the large particle sizes from 100 down to about $10 \mu \mathrm{m}$ are in good agreement with experimental data. However, particles smaller than about $10 \mu \mathrm{m}$ are not predicted very well. In Fig. 4, showing "snapshots" after 47 and 119 hours of dispersion, the agreement is good for the small particles, but less good for the "large" particles (at this point in dispersion time between about 1 and $10 \mu \mathrm{m})$. It is interesting that, despite the good agreement for all values of time in Fig. 2, the full PSDs are not quantitatively described. This can be attributed to the data in Fig. 2 being mean values, where deviations for the smallest agglomerates will not weigh to any great extent in the calculations. This was further verified by conducting a modified simulation ("extended"), where more model parameters were allowed to vary. It was chosen to let the distribution of eroded fragments from each agglomerate have a characteristic particle size, $d_{c, j}$, three times smaller than the arithmetic mean value used in the Base Case (and given by eq 8) for the first 10 hours of the dispersion experiment. The modified simulation is shown with dashed lines in Fig. 2 (top plot) and Fig. 3 and 4. It is evident that a better match is obtained for the full PSDs, but also that the effect on the mean agglomerate diameter (Fig. 2, top) is quite small.

The $d_{v 90}$ and $d_{v 99}$ values (defined as agglomerate diameters below which 90 and $99 \%$, respectively, of the particle volume is found), also of significant practical interest (large agglomerates are undesired), are provided in Table 1 . It can be seen that a reasonably good agreement 
is obtained, but also that the values are only slightly improved from the one to the multiple parameter model. It should be stressed that the "extended" model is just another way of distributing erosion fragments to smaller particle classes in the first 10 hours of dispersion and that other successful combinations of those parameters may be possible. It seems likely that fragment size distributions could be different in the initial phases where very large changes in agglomerate sizes are seen, but this is only indirectly seen via the PSDs and has not been confirmed. Rwei et al. $(1991)^{26}$ have shown that the larger the agglomerate diameter, the larger the erosion fragments formed and that there can be a "less heterogeneous distribution of cohesivity of particles bound at the surface."

Another point of interest is that the largest agglomerates in the PSDs in Fig. 4 erode faster than and "overtake" the experimental values at long dispersion times. This may be attributed to the model assumption of agglomerate stability against erosion being the same for all agglomerates of the same size. In the experiments, some of the "large" agglomerates left at this point in time may be tougher to erode than the ones (of same size) already displaced to smaller size fractions. This is in good agreement with the findings of Horwatt et al. ${ }^{27}$, that initially weak points in the agglomerates fail and that strong portions of an agglomerate may resist dispersion. As a consequence of this, additional model parameters would need to be introduced to "halt" the simulated dispersion at long dispersion times and enable a match of simulations and experiments. Alternatively, the emergence of an increased discrepancy between model and experiment at long times may be used to help taking the decision on when to stop the dispersion, due to mainly tough agglomerates remaining, and thereby save time and energy, but this practical application was not investigated further.

In summary, using $\mathrm{n}=2$, the arithmetic mean for fragment distribution via Weibull, and treating the erosion rate constant, $\mathrm{k}_{\mathrm{d}}$, as the only adjustable parameter in the dispersion model seems sufficient to get a good estimation of the transient development in the volume-moment mean and $d_{v 90}$ or $d_{v 99}$ agglomerate diameters. This approach will keep the model simple and 
not require further details on fragment distribution. In later sections, the reliability of this approach will be investigated for two other pigments.

\section{Frequency distributions and sensitivity analysis}

The model can also simulate the agglomerate frequency distribution, which is useful for evaluation of details in the PSDs. Results for four values of dispersion time are shown in Fig. 5. It is evident that the bimodal distribution, seen after 5 hours, over time tends progressively towards a monomodal distribution. This development was also found in the experimental data of $\mathrm{B}^{8} \mathrm{~L}^{8}$ (not shown). In McCarvey et al. ${ }^{8}$, only frequency distributions in $\%$ are available, whereas the simulations in Fig. 5 are provided with $d V / d \log \left(d_{p}\right)$ as the y-axis coordinate, whereby the area under each curve equals unity. Simulations cannot be compared directly with the experimental data because the interval widths used by McCarvey et al. ${ }^{8}$ are unknown. It was investigated (not shown) if simulations were sensitive to the choice of cumulative fraction distribution function, $\mathrm{F}\left(\mathrm{d}_{\mathrm{p}, \mathrm{j}}\right)$, selected. A Weibull distribution (eq 7) is used in the model, but also log-normal and normal distributions (as used e.g. by Rwei et al. ${ }^{26}$ ) were tried with arithmetic mean values for the characteristic parameter of the distributions. It turns out that the model is practically insensitive to the choice of distribution. The reason is that the "width" of the distribution in all cases needs to be very narrow to ensure that the cumulative fraction distribution has reached unity at (or before) the pertinent diameter, $d_{p, j}$. If this is not the case, the volume balance will not close (i.e. all the eroded volume of a particle needs to be displaced to smaller size fractions and this is ensured via the "width parameter" of a given distribution). With such steep cumulative distributions, the choice of distribution function is not important. If values lower than the arithmetic particle mean are used in the log-normal or normal distributions, then too many small agglomerates are formed, in disagreement with experimental data. The Weibull distribution is recommended over the other distribution functions because eq (7) is very straight forward to use. The normal and log-normal distribution functions both require evaluation of the so-called error function. 
The sensitivity of the model with respect to the erosion rate constant, $\mathrm{k}_{\mathrm{d}}$, and the characteristic particle size, $d_{c, j}$, is shown in Fig. 6 . In the top plot, $d_{c, j}$ has been reduced to 50 and $25 \%$ of the Base Case value used in Figs 2-5, respectively. It can be seen that rather large changes are required for significant effects. It is not possible to match experimental data using $d_{c, j}$ values lower than the arithmetic mean and adjusting $\mathrm{k}_{\mathrm{d}}$. This produces too many small agglomerates at long dispersion times (not shown). In Fig. 6 (bottom plot), a strong effect from $\mathrm{k}_{\mathrm{d}}$ is evident. This very model-sensitive parameter seems a good choice for an adjustable parameter and all pigment-specific parameters are lumped into the value of $\mathrm{k}_{\mathrm{d}}$. The changes seen in Fig.

6 for $\mathrm{k}_{\mathrm{d}}$ could correspond to e.g. the use of a different apparatus for dispersion or other operational parameters (leading to higher or lower shear rates) or a different vehicle viscosity. Mapping of the effect of pigment-specific and equipment-specific parameters on $\mathrm{k}_{\mathrm{d}}$ would be a very useful extension of the model, but this requires extensive sets of additional experimental data and was not attempted here.

\section{Transient developments in size fractions}

Finally, in Fig. 7, the transient developments (in the first 20 hours) in three size fractions are shown for Pigment Yellow B3L pigment. The smallest, the largest, and an intermediate size fraction were selected. It can be seen that the largest agglomerates disappear within the first two hours. Due to agglomerates being formed via fragments from larger agglomerates and due to agglomerates eroding to smaller sizes, the intermediate size fraction increases for the first three hours and then slowly disappears during the subsequent 16 hours. The smallest size fraction, consisting of primary particles, increases continuously because these agglomerates (particles) cannot become smaller than their present size (equal to $\mathrm{d}_{\mathrm{p}, \mathrm{min}}$ ). The simulated time it takes for all agglomerates to be broken down (i.e. less than one agglomerate remaining per $\mathrm{m}^{3}$ mill base) to primary particles, under the conditions of Fig. 7 , is 8700 hours (i.e. about one year!). This long time is due to the smallest agglomerates eroding very slowly. Dispersion time would never be taken to such an extreme in practice and small agglomerates would be 
allowed, in good agreement with the experimental findings of Hornby and Murley ${ }^{18}$ and Brisson et al. 5 .

\section{Model verification using data for Pigment Yellow 13 LBG}

The second pigment that is considered for model verification is Pigment Yellow 13 LBG. According to McGarvej et al. ${ }^{8}$, this pigment disperses more readily than B3L.

\section{Mean agglomerate size over time and full particle size distributions}

The transient development in mean agglomerate diameter of LBG in a ball mill is shown in Fig. 8. Notice that the ball milling time is the same as for B3L (119 hours), but that the initial mean diameter is only about $9.3 \mu \mathrm{m}$, as opposed to $21.3 \mu \mathrm{m}$ for B3L. After 119 hours, the experimental mean diameter is $0.72 \mu \mathrm{m}$ for $\mathrm{LBG}$ and $1.17 \mu \mathrm{m}$ for $\mathrm{B} 3 \mathrm{~L}$. Good agreement is seen between simulation and experimental data in Fig. 8, when using $\mathrm{n}=2$ in the model meaning that also for LBG the linear erosion rate is proportional to the external agglomerate surface area. The erosion rate constant, $\mathrm{k}_{\mathrm{d}}$, was adjusted to $3.3 \mathrm{~m}^{-1} \cdot \mathrm{s}^{-1}$, about twice the value of $\mathrm{k}_{\mathrm{d}}$ for B3L $\left(1.81 \mathrm{~m}^{-1} \cdot \mathrm{s}^{-1}\right)$, confirming the statement by McGarvej et al. ${ }^{8}$ that LBG disperses more readily than $\mathrm{B} 3 \mathrm{~L}$. In practice, this can be attributed to a faster "levelling out" of the transient experimental data (from about 50 to 120 hours) in Fig. 8 (LBG) compared to those in Fig. 2 (B3L) (notice the different scaling on the y-axis of the two figures, which makes it difficult to compare the data directly, but when plotted in the same figure the difference can be clearly seen).

Comparison of simulations and experimental data for the full agglomerate PSDs are shown in Fig. 9 and 10 for four values of dispersion time. A reasonably good agreement is seen, but also for this pigment some discrepancy is evident for the small agglomerates during the initial phases. As for B3L, a better match (not shown) can be obtained by introducing a timedependent fragment distribution, but the mean and maximum agglomerate diameters are only 
affected to a small extent (not shown) and it seems appropriate to keep the model simple with $\mathrm{n}=2$ and $\mathrm{k}_{\mathrm{d}}$ as the only adjustable parameter.

\section{Frequency distributions}

Frequency distributions for LBG are shown in Fig. 11. Also for this pigment, the initially bimodal distribution tends progressively towards monomodal as observed in practice by McGarvej et al. ${ }^{8}$.

\section{Model verification using data for Pigment Red DPP}

The last experimental series was taken from an independent study with Pigment Red DPP in an acrylic binder (ink), dispersed on a three-roll mill. The primary particles of red DPP pigment are flakes with a d/l (0.15-0.6 um/0.05-0.07 um) of about 10 .

For this pigment, the transient development in mean agglomerate diameter is much less than for the two previous pigments as shown in Fig. 12. Simulations were fitted to the experimental data by simply treating the tree-roll mill as a batch dispersion. This simplistic approach means that no details of the process flows were used as input to the model and that equipment numbers are lumped into the value of $\mathrm{k}_{\mathrm{d}}$. It can be seen that the experimental data can be matched by the model with $n=0,1,2$, or 3 and it is not possible to extract details of the erosion mechanism from Fig. 12. However, when looking at the full PSDs in Fig. 13, it can be seen that a good match of the smallest particle classes is only possible when using $n=2$ or 3 confirming that also in this case the erosion process depends on agglomerate external surface area $(n=2)$ (or agglomerate volume, $n=3$ ). The maximum agglomerate diameter is also well described.

\section{Evaluation of model assumptions}

The model is based on a number of simplifying assumptions that will now be readdressed. The most important assumption is probably that of no agglomerate rupture (i.e. break up) tak- 
ing place during dispersion. Rupture could potentially be an important mechanism, in particular in the first part of the dispersion process, where the simple model $(n=2)$ does not predict the many small agglomerates being formed. Rwei et al. ${ }^{28}$ mention that in their studies, coarse rupturing occurs in the early stages and later more gradual erosion occurs and that once erosion starts, it continues for very long times. Rupture occured shortly after reaching a critical stress and concluded abruptly. Wahl et al. ${ }^{7}$ (in their Fig. 3) have also discussed how agglomerates are a function of both size and bonding strength distribution. However, the assumption of no rupture taking place is not crucial if only mean agglomerate diameters and/or $\mathrm{d}_{\mathrm{v} 90}$ and $\mathrm{d}_{\mathrm{v} 99}$ are of interest (at least not for the pigments considered in this work). The assumption has not been confirmed directly in any way. The importance of a rupture mechanism (as opposed to surface erosion) may in principle be a function of both dispersion time and agglomerate diameter. It will therefore be difficult to work with in practice, but it is likely that very easily dispersible agglomerates could simply fall apart into many smaller agglomerates or even primary particles in the initial stages of a dispersion. The long term (119 hours) and gradual development of bimodal PSDs into monomodal PSDs seen for B3L and LBG pigments in this work seem more likely to be dominated by surface erosion. Larger filler agglomerates at high shear rates, for instance, could be more influenced by rupture mechanisms, but this was not investigated.

It was assumed that all agglomerates, erosion fragments, and primary particles are spherical. This is probably a reasonable assumption for most agglomerates (see e.g. the micrographs for DPP in Fig. 4 in Van et al. ${ }^{25}$ ), but the primary particles can be e.g. platy or acicular. The laser diffraction measurements convert the particle (agglomerate) volume to an equivalent spherical volume and calculates an associated spherical volume diameter so this is taken into account, but how and if it affects the mechanism of dispersion has not been investigated.

It was assumed that binder penetration into agglomerates does not influence the rate of dispersion. This is in good agreement with data from Lee et al. ${ }^{11}$, where it was found that only for very high porosities, higher than $65 \%$, does it play a role. The lower the porosity (pore diame- 
ters), the higher the penetration rate, according to Washburns equation ${ }^{29}$. In addition, for a surface-erosion controlled process, the rate of penetration into the bulk of the agglomerate should not be of importance.

It was also investigated if another linear erosion rate expression (instead of eq 5) could be used. It is given by

$$
-\frac{d\left(d_{p, j}\right)}{d t}=k_{d}\left(1+a d_{p, j}\right)^{n}
$$

where a is an additional empirical constant that must be fitted. However, it was not possible to obtain a good fit with this rate expression.

In eq (5) (with $n=2$ ), the rate is related to the external surface area of a sphere, but in reality, the agglomerates will have a rough surface. However, the model will not be practical if the (unknown) roughness needs to be included and the roughness factor is (together with other parameters) lumped into the value of $\mathrm{k}_{\mathrm{d}}$.

It was assumed that no primary particles are broken in the dispersion process. This seems a reasonable assumption because primary particles are held together (cohesion) by chemical bonds, unlike agglomerates where physical bonds hold the individual particles together. As stated earlier, chemical bonds are about 10 times stronger than physical bonds.

\section{Practical use of the model}

The one-parameter model can be used in the following way. A dispersion experiment is followed over time by taking samples at selected intervals. PSD measurements are conducted on the samples and $\mathrm{D}[4,3]$ (and/or $\mathrm{d}_{\mathrm{v} 90}$ or $\mathrm{d}_{\mathrm{v} 99}$ ) is plotted as a function of time (as shown in Fig. 2). The erosion rate constant, $k_{d}$, is adjusted so that the model simulation (with $n=2$ ) and experimental data match. If a satisfactory agreement cannot be obtained, other values of $\mathrm{n}$ (e.g. $\mathrm{n}=3$ ) can be tried (and if this also does not work well, the erosion mechanism is not the same as in the case studies of this work). Different pigments, examined in the same dispersion equipment at the same temperature, can then be compared quantitatively via the values of $k_{d}$. 
A larger value of $\mathrm{k}_{\mathrm{d}}$ means a faster dispersion rate. With a proper "calibrated" (i.e. $\mathrm{k}_{\mathrm{d}}$ values for various pigments) model, it is also possible to use it as a supporting diagnostic tool when faced with dispersion failures.

One limitation of the present approach is that accurate PSD measurement equipment is needed. However, compact laser diffraction based table-size equipment is now available in most companies working with dispersion of pigments. At-line or on-line versions, which can be used for production purposes and continuous quality control, can also be found ${ }^{33}$. Due to its reliability in detecting oversized agglomerates (often present in very small numbers that may not be "seen" in a diluted dispersion by laser diffraction ), the primitive grindometer will probably be hard to avoid completely in coating production, but as shown in this work, additional relevant information can be obtained when working with full agglomerate PSDs.

\section{Conclusions}

A transient mathematical model describing the dispersion of pigment agglomerates in dispersion equipment (ball and three-roll mill) has been developed. Using some simplifying assumptions (e.g. second order linear erosion rate), a single adjustable parameter (erosion rate constant, $\mathrm{k}_{\mathrm{d}}$ ), and taking into account the full PSD, it was possible to provide a quantitative description of the transient development in the volume-moment mean, $d_{v 90}$, and $d_{v 99}$ agglomerate diameters for three pigments considered. The model involves the solution of 70 coupled ordinary differential equations, but is not limited by computation time (less than one minute on a "standard" PC).

An important point for further work is to map the influence of equipment parameters (e.g. stirrer type, rotation speed, the $\alpha$ parameter, or ball size), temperature, and other process parameters on the value of $k_{d}$. Is it possible to handle all these effects via $k_{d}$ or will other mechanisms than surface erosion play a role, whereby the model needs to be extended?

The potential general validity of $n=2$ should also be confirmed, in particular for inorganic pigments and for pigments with odd size primary particles (e.g. acicular). 


\section{A final note on terminology}

It should be mentioned (warned) that the terminology is not very consistent in the field of dispersion. In most books (e.g. Winkler ${ }^{1}$ ) and articles related to coatings, including this one, the term "agglomerate" is used to describe particles that are held together in a group by physical van der Waals forces and that can be dispersed. The term "aggregate" is used to describe a group of particles sintered together during processing, bound by chemical bounds, and that can only be milled (typically meaning a low quality pigment powder). However, other references, in particular outside the coatings community, more or less ignore the word "agglomerate" and use only "aggregate" (and/or "flocculate") in the discussion of particle (or droplet) dispersion.

\section{Acknowledgements}

Financial support by The Hempel Foundation is gratefully acknowledged. 


\section{References}

1. Winkler, J, “Dispersing pigments and fillers”, Hannover, Germany, Vincentz, 2012

2. Netzsch homepage. "In-line Disperser". Netzsch-grinding.com. Accessed December 2015

3. Silverson home page. "In-line mixers for dispersion". Silverson.com. Accessed March 2016

4. Ystral home page. "In-line mixers for dispersion”. Ystral.com. Accessed March 2016

5. Brisson, A, L'Espérance, G, Caron, M, 'Use of an image analysis technique to quantify pigment dispersion, J. Coat. Technol. 63(801) 111-118 (1991)

6. Hall, JE, Benoit, R, Bordelieau, R., Rowland, R, "Quantifying pigment dispersion”, J. Coat. Technol., 60(756) 49-61 (1988)

7. Wahl, E.F., Pangborn, G.G., McCurdy, H.A. "Dynamic analysis and mathematical modeling of the high-speed dispersion system”, J. Paint Tech., 44(564) 98-107 (1972)

8. McGarvey, M, Mcgregor, D, McKay, RB, "Particle size analysis by laser diffraction in organic pigment technology”, Prog. Org. Coat. 31 223-228 (1997)

9. Winkler, J, Klinke, E, Dulog, L, "Theory of the deagglomeration of pigment clusters in dispersion machinery by mechanical forces. 1." J. of Coat. Technol., 59(754) 35-41 (1987)

10. Bohin, F, Manas-Zloczower, I, Feke, DL, "Kinetics of dispersion for sparse agglomerates in simple shear flows: application to silica agglomerates in silicone polymers", Chem. Eng. Sci., 51 5193-5204 (1996)

11. Lee, YJ, Feke, DL, Manas-Zloczower, I, "Dispersion of titanium dioxide agglomerates in viscous media", Chem. Eng. Sci., 48(19) 3363-3372 (1993)

12. Lozano, T, Lafleur, PG, Grmela, M, Vergnes, B, "Modeling filler dispersion along a twin-screw extruder", Intern. Polymer Proc. XVIII, 1, 12-19 (2003)

13. Lee, SH, Jung, MH, Choi, C, Moon, H, Chung, CB, "Modeling of a bead mill process for dispersion of coagulated nano particles", Powder Technology, 233 96-102 (2013)

14. Potente, H, Kretschmer, K, Flecke, J, “A physical-mathematical model for the dispersion process in continuous mixers", Polym Eng. Sci. 42(1) 19-32 (2002)

15. Flecke, J, Potente, H, Kretschmer, K, "A physical-matematical model for the dispersion process in a co-rotating intermeshing twin screw extruder", J. Reinforced Plast. Comp., 21(6) (2002)

16. Baldyga, J, Orciuch, W, Makowski, L, Malik, K, Ozcan-Taskin, G, ” Dispersion of nanoparticle clusters in a rotor-stator mixer", Ind. Eng. Chem. Res., 47(10), 36523662 (2008)

17. Baldyga, J, Makowski, L, Orciuch, W, Sauter, C, Schuchmann, HP, "Deagglomeration processes in high-shear devices”, Chem. Eng. Res. Des., 86, 1369-1381 (2008) 
18. Hornby, MR, Murley, RD, "An electron microscopy study of titanium dioxide in paint films", J. Oil. Colour Chemists' Assoc., 52 1035-1040 (1969)

19. Potente, H, Kretschmer, K (2002) "Simulation and evaluation of compounding processes”, Macrom. Mater. Eng., 287 758-772 (2002)

20. Kiil, S, Michelsen, ML, Dam-Johansen, K "Experimental Investigation and Modelling of a Wet Flue Gas Desulphurisation Pilot Plant”, Ind. Eng. Chem. Res., 37 2792-2806 (1998)

21. Vesilind, PA, "The Rosin-Rammler particle size distribution", Resource, Recovery and Conservation, 5 275-277 (1980)

22. Hansen, BB, Kiil, S, Johnsson, JE “Quantification of gypsum crystal nucleation, growth, and breakage rates in a wet flue gas desulfurization pilot plant", A.I.Ch.E. J., 55(10) 2746-2753 (2009)

23. Seville, J.P.K., Tüzun, U., Clift, R., "Processing of particulate solids", Chapter 1, Blackie Academic \& Professional, London, (1997)

24. Press, WH, Teukolsky, SA, Vetterling, WT, Flannery, BP, "Numerical Recipes in Fortran", $2^{\text {nd }}$ ed., Cambridge University Press, 1994

25. Van, ST, Velamakanni, BV, Adkins, RR, "Comparison of methods to assess pigment dispersion”, J. Coat. Technol., 73(923) 61-70 (2001)

26. Rwei, SP, Manas-Zloczower, I, Feke, DL, "Characterization of agglomerate dispersion by erosion in simple shear flows”, Polym Eng. Sci. 31(8) 558-562 (1991)

27. Horwatt, SW, Feke, DL, Manas-Zloczower, I, “The influence of structural heterogeneities on the cohesivity and breakup of agglomerates in simple shear flow", Powder Technol. 72 113-119 (1992)

28. Rwei, SP, Manas-Zloczower, I, "Analysis of dispersion of carbon black in polymeric melts and its effect on compound properties”, Polym Eng. Sci. 32(2) 130-135 (1992)

29. Washburn, EW, "The dynamics of capillary flow", Physical Review, 17(3) 273-283 (1921)

30. Shiga, S, Furuta, M, "Processability of electron-paramagnetic-res in an internal mixer. 2. Morphological changes of carbon black agglomerates during mixing", Rubber Chem. Technol, 58(1) 1-22 (1985)

31. Kasaliwal, GR, Pegel, S, Goldel, A, Potschke, P, Heinrich, G, “Analysis of agglomerate dispersion mechanisms of multiwalled carbon nanotubes during melt mixing in polycarbonate", Polymer, 51 2708-2720 (2010)

32. McGarvey, M, McKay, RB, "Physical characterization of organic pigment powders", Surf. Coat. Int. (9) 435-440 (1997)

33. Malvern home page. "Insitec Wet". Malvern.com. Accessed March 2016 
Table 1 Experimental data and simulations of the $d_{v 90}$ (top) and $d_{v 99}$ (bottom) for Pigment Yellow B3L at four values of dispersion time. Conditions are those of Fig. 2-4 and $n=2$ was used to obtain the simulated values. All agglomerate diameters in the table are provided in $\mu \mathrm{m}$.

\begin{tabular}{|c|c|c|c|}
\hline $\begin{array}{l}\text { Dispersion } \\
\text { time (hours) }\end{array}$ & $\begin{array}{c}\text { Simulation } \\
\text { (one- } \\
\text { parameter } \\
\text { model), } \\
d_{\mathrm{v} 90}\end{array}$ & $\begin{array}{c}\text { Simulation } \\
\text { (multiple- } \\
\text { parameter } \\
\text { model), } \\
d_{\mathrm{v} 90}\end{array}$ & $\begin{array}{c}\text { Experimenta } \\
\text { data, } \\
d_{\mathrm{v} 90}\end{array}$ \\
\hline 5 & 17 & 19 & 20 \\
\hline 15 & 8 & 8.5 & 7 \\
\hline 47 & 3 & 3.5 & 4.6 \\
\hline 119 & 1.3 & 1.5 & 2.3 \\
\hline
\end{tabular}

\begin{tabular}{|c|c|c|c|}
\hline $\begin{array}{c}\text { Dispersion } \\
\text { time (hours) }\end{array}$ & $\begin{array}{c}\text { Simulation } \\
\text { (one- } \\
\text { parameter } \\
\text { model), } \\
\mathbf{d}_{\mathbf{v} 99}\end{array}$ & $\begin{array}{c}\text { Simulation } \\
\text { (multiple- } \\
\text { parameter } \\
\text { model), } \\
\mathbf{d}_{\mathbf{v} 99}\end{array}$ & $\begin{array}{c}\text { Experimental } \\
\text { data, } \\
\mathbf{d}_{\mathbf{v} 99}\end{array}$ \\
\hline 5 & 29 & 35 & 40 \\
\hline 15 & 13 & 16 & 14 \\
\hline 47 & 5 & 5.5 & 8 \\
\hline 119 & 2.5 & 2.6 & 4 \\
\hline
\end{tabular}


Figure captions and figures

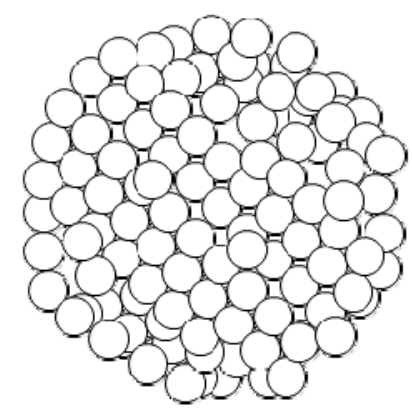

Plgment agglomerate
Surface erosion

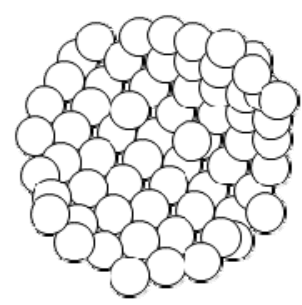

Surface-eroded

plgment agglomerate

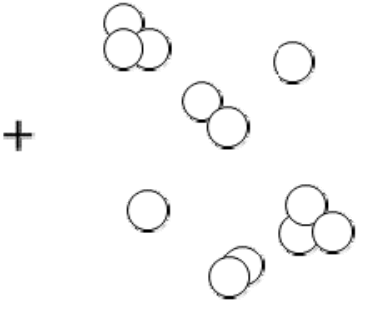

Smaller

plgment

agglomerates

Fig. 1 Schematic illustration of the mechanical disruption step in a pigment dispersion, where pigment agglomerates are reduced in size by surface erosion ("onion-peeling mechanism ${ }^{, 30,31}$ ). Smaller agglomerates, in a distribution of sizes, are formed as erosion fragments. Spherical agglomerates and primary particles are used in the model and in the illustration, but other shapes (e.g. plate, rod, or cube/brick ${ }^{32}$ ) are possible for the primary particles (in particular for organic pigments) and agglomerates can also deviate, to some extent, from the spherical shape. 


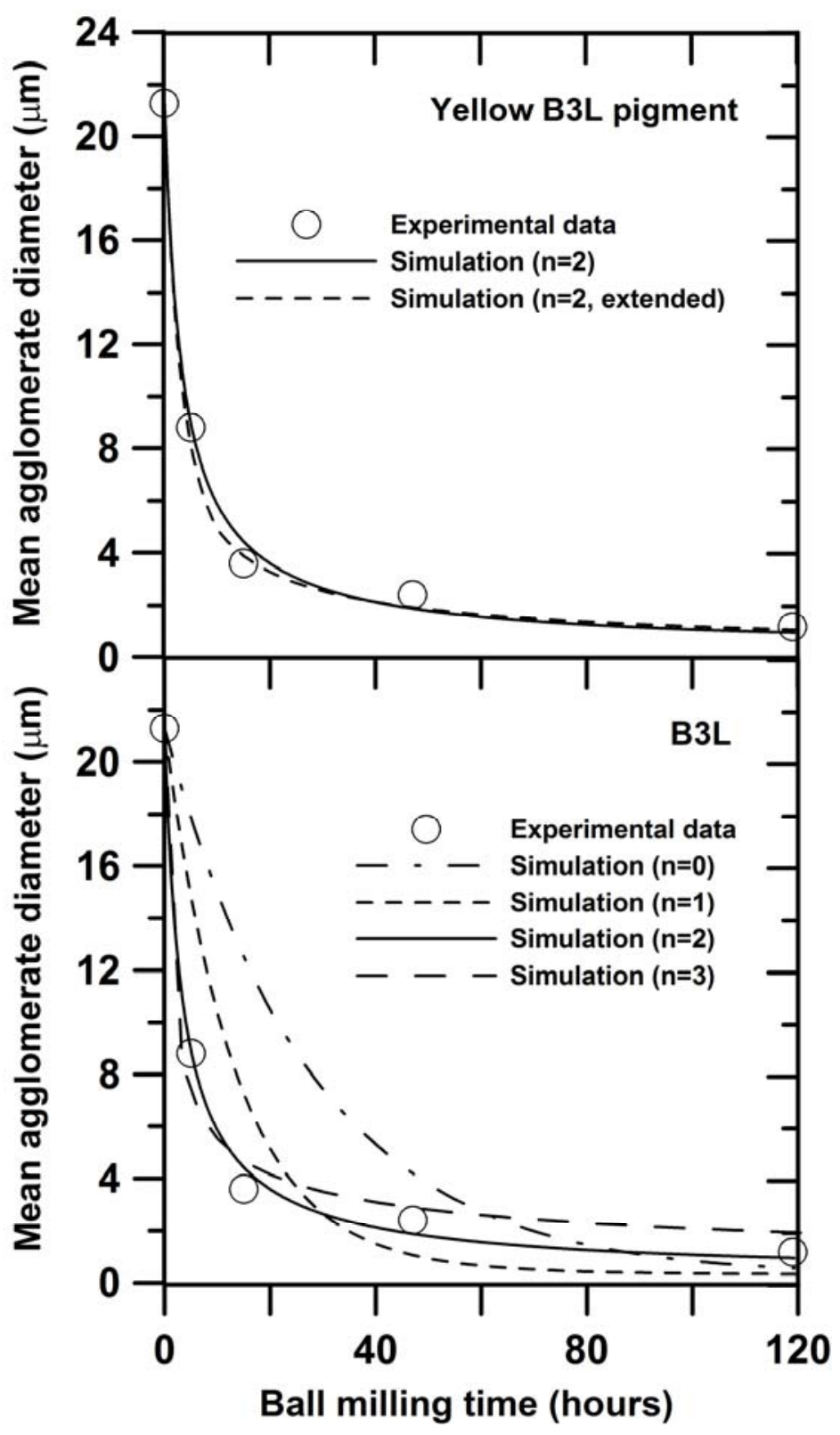

Fig. 2 Volume-moment mean diameter, D[4,3], as a function of ball milling time for Pigment Yellow B3L pigment. The bottom plot shows the effect of the rate order, $n$ (see eq 5). The values of $\mathrm{k}_{\mathrm{d}}$ used are: $1.82 \cdot 10^{-10} \mathrm{~m} \cdot \mathrm{s}^{-1}(\mathrm{n}=0), 1.63 \cdot 10^{-5} \mathrm{~s}^{-1}(\mathrm{n}=1), 1.81 \mathrm{~m}^{-1} \cdot \mathrm{s}^{-1}(\mathrm{n}=2), 1.65 \cdot 10^{5}$ $\mathrm{m}^{-2} \cdot \mathrm{s}^{-1}(\mathrm{n}=3)$. The top plot shows the effect of using one $\left(\mathrm{k}_{\mathrm{d}}=1.81 \mathrm{~m}^{-1} \cdot \mathrm{s}^{-1}\right.$, solid line $)$ as opposed to several adjustable parameters ("extended", $\mathrm{k}_{\mathrm{d}}=0.17 \mathrm{~m}^{-1} \cdot \mathrm{s}^{-1}, \mathrm{~d}_{\mathrm{c}, \mathrm{j}}=\mathrm{d}_{\mathrm{c}, \mathrm{j}}$ arithmetic mean $/ 3$ for $\mathrm{t}<\mathrm{t}_{\mathrm{c}}, \mathrm{d}_{\mathrm{c}, \mathrm{j}}=\mathrm{d}_{\mathrm{c}, \mathrm{j}}$ arithmetic mean for $\mathrm{t}>\mathrm{t}_{\mathrm{c}}, \mathrm{t}_{\mathrm{c}}=10$ hours, see main text for explanation). In the simulation, $\mathrm{C}_{\mathrm{P}}=210 \mathrm{~kg} / \mathrm{m}^{3}, \rho_{\text {pigment }}=1500 \mathrm{~kg} / \mathrm{m}^{3}$, and $\varepsilon_{\mathrm{A}}=0.20$ (these three parameters do not influence the simulations in Fig. 2, only the number distribution is affected). $\alpha=0.5$ and $d_{p, \min }=0.1 \mu \mathrm{m}$. 


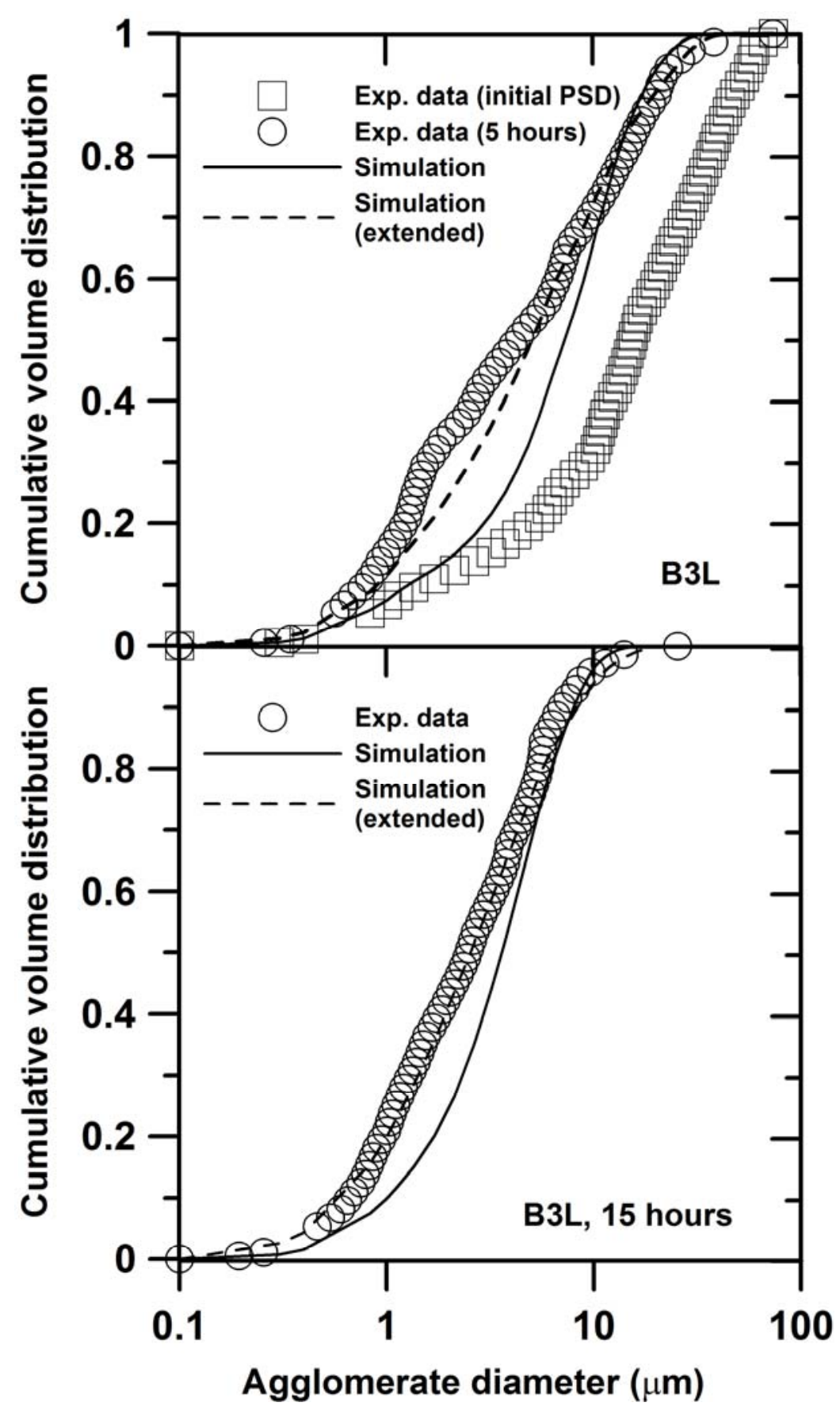

Fig. 3 Comparison of simulations and experimental data for two values of dispersion time (5 and 15 hours) for B3L pigment. In the top plot, also the initial PSD, which serves as an input to simulations, is shown. In all simulations shown, $\mathrm{n}=2$. The solid lines represent simulations when using only one adjustable parameter $\left(\mathrm{k}_{\mathrm{d}}=1.81 \mathrm{~m}^{-1} \cdot \mathrm{s}^{-1}\right)$. The dashed lines are simulations where several adjustable parameters $\left(k_{d}, d_{c, j}\right.$, and $\left.t_{c}\right)$ were used (values applied are provided in the caption of figure 2). 


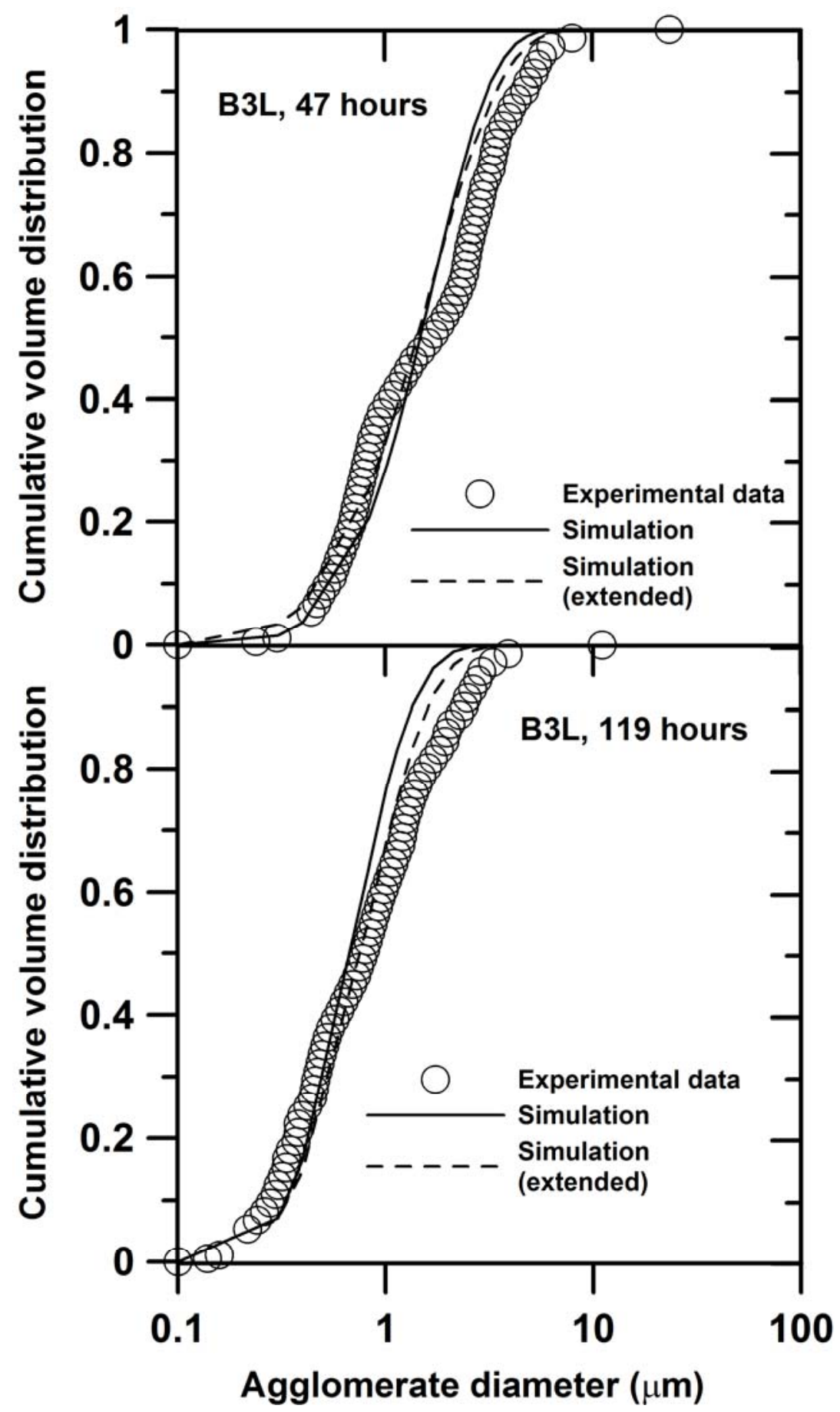

Fig. 4 Comparison of simulations and experimental data for two values of dispersion time (47 and 119 hours) for B3L pigment. In all simulations shown, $\mathrm{n}=2$. The solid lines represent simulations when using only one adjustable parameter $\left(\mathrm{k}_{\mathrm{d}}=1.81 \mathrm{~m}^{-1} \cdot \mathrm{s}^{-1}\right)$. The dashed lines ("extended") are simulations where several adjustable parameters $\left(\mathrm{k}_{\mathrm{d}}, \mathrm{d}_{\mathrm{c}, \mathrm{j}}\right.$, and $\left.\mathrm{t}_{\mathrm{c}}\right)$ were used (values applied are provided in the caption of figure 2). 


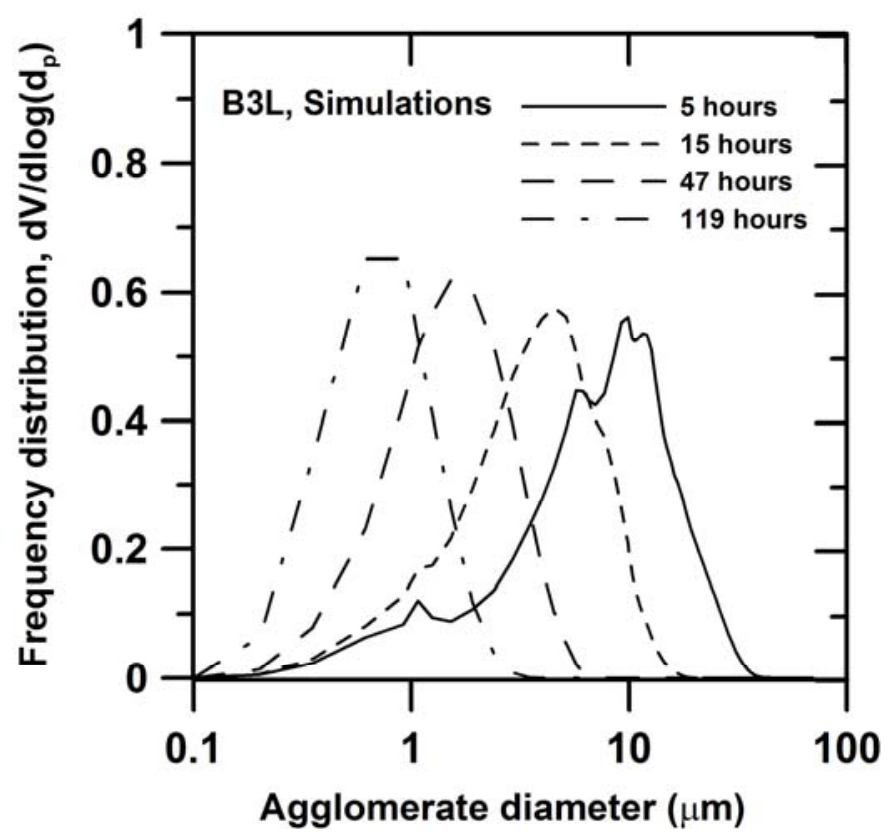

Fig. 5 Simulated frequency distribution for Yellow B3L for four values of dispersion time. The initial distribution $(\mathrm{t}=0)$ is not shown because of "noisy" appearance. Parameters are $\mathrm{n}=2$ and $\mathrm{k}_{\mathrm{d}}=1.81 \mathrm{~m}^{-1} \cdot \mathrm{s}^{-1}$ (corresponding to the simulations in Fig. 3 and 4). The area under each of the curves is equal to unity. 


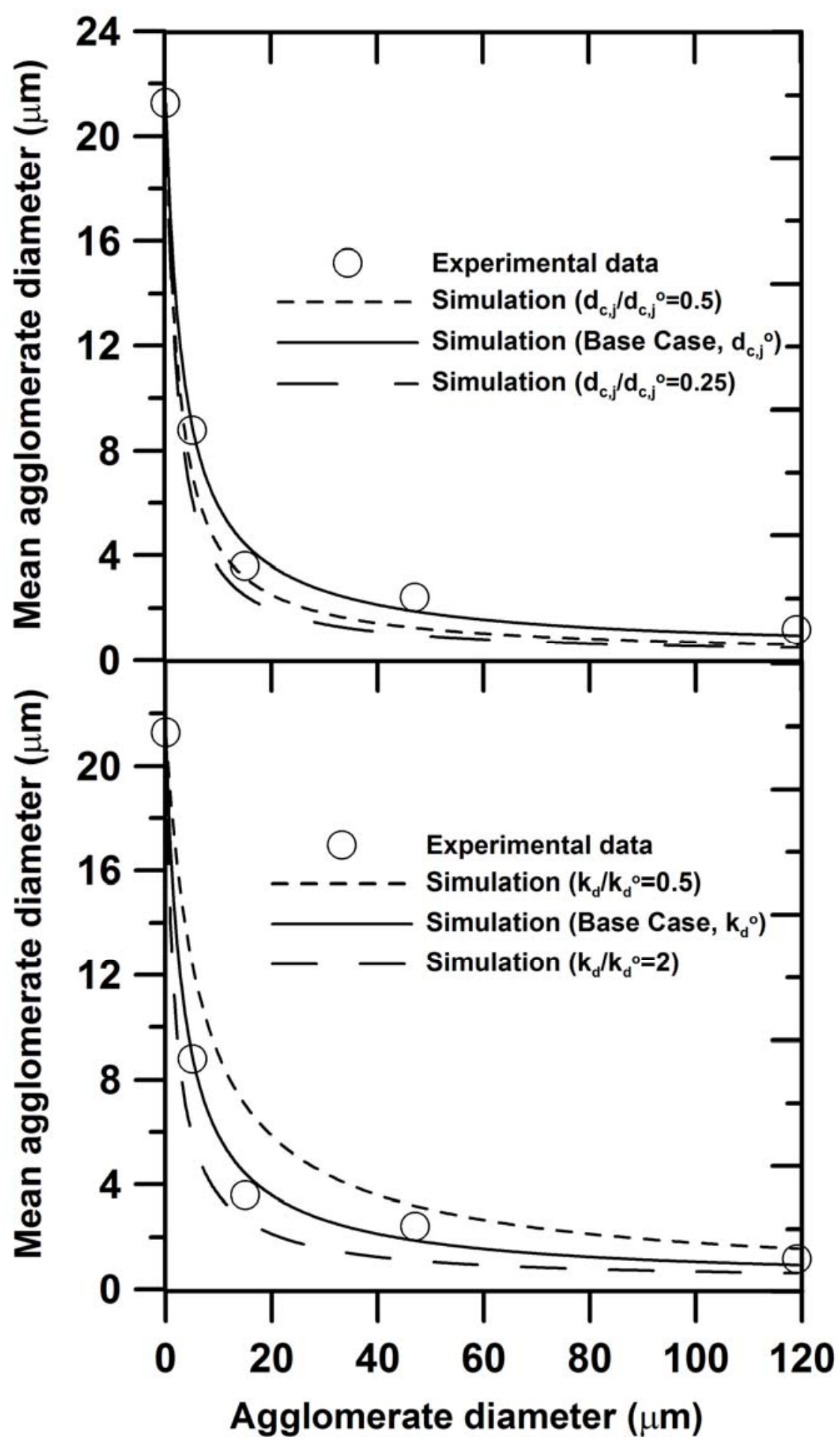

Fig. 6 Effect of erosion rate constant, $\mathrm{k}_{\mathrm{d}}$, (bottom) and the characteristic particle size, $\mathrm{d}_{\mathrm{c}, \mathrm{j}}$, (top) on volume-moment mean diameter as a function of ball milling time for Pigment Yellow B3L pigment. In all simulations, $\mathrm{n}=2$. Base Case values are $\mathrm{k}_{\mathrm{d}}{ }^{\mathrm{o}}=1.81 \mathrm{~m}^{-1} \cdot \mathrm{s}^{-1}$ and $\mathrm{d}_{\mathrm{c}, \mathrm{j}}{ }^{\mathrm{o}}$ given by equation (8) (i.e. the arithmetic mean value), where $\mathrm{j}=1, . ., \mathrm{M}$ refers to the discretization points. In the top plot, $\mathrm{k}_{\mathrm{d}}=\mathrm{k}_{\mathrm{d}}{ }^{\mathrm{o}}$ and in the bottom plot, $\mathrm{d}_{\mathrm{c}, \mathrm{j}}=\mathrm{d}_{\mathrm{c}, \mathrm{j}}{ }^{\mathrm{o}}$. 


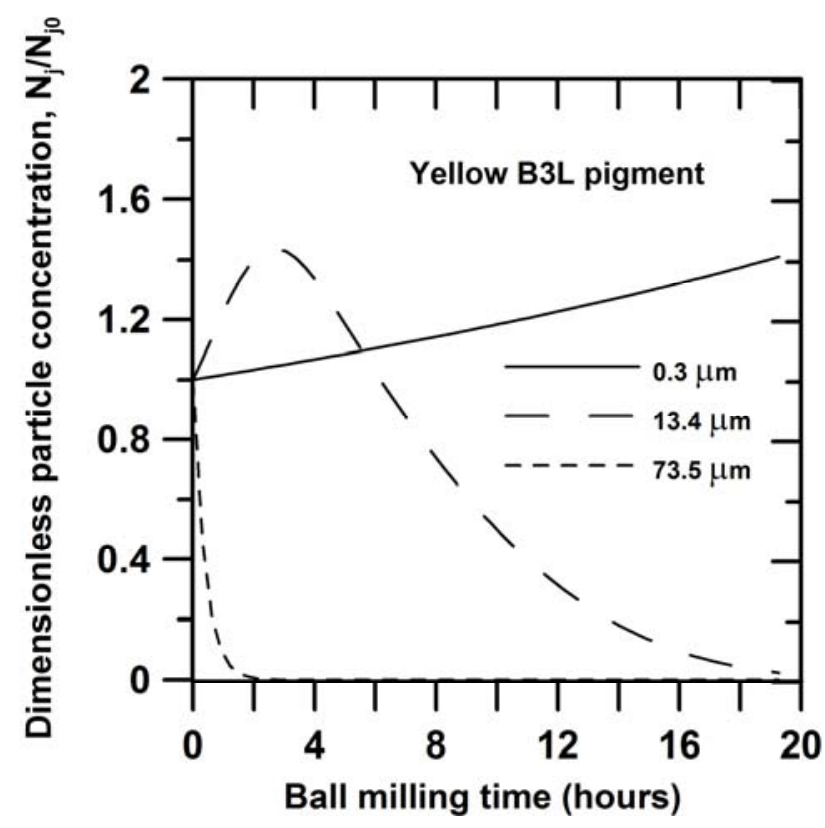

Fig. 7 Dimensionless particle number concentration as a function of ball milling time for three B3L agglomerate diameters (the largest, the smallest, and an intermediate value in the distribution). The actual particle diameters provided in the legend are the right hand side values of the relevant particle class. The $0.3 \mu \mathrm{m}$ size class corresponds to the interval where primary particles are placed. Notice that ball milling time only runs up to 20 hours in this plot. $n=2$. Other parameters as in Fig. 2. 


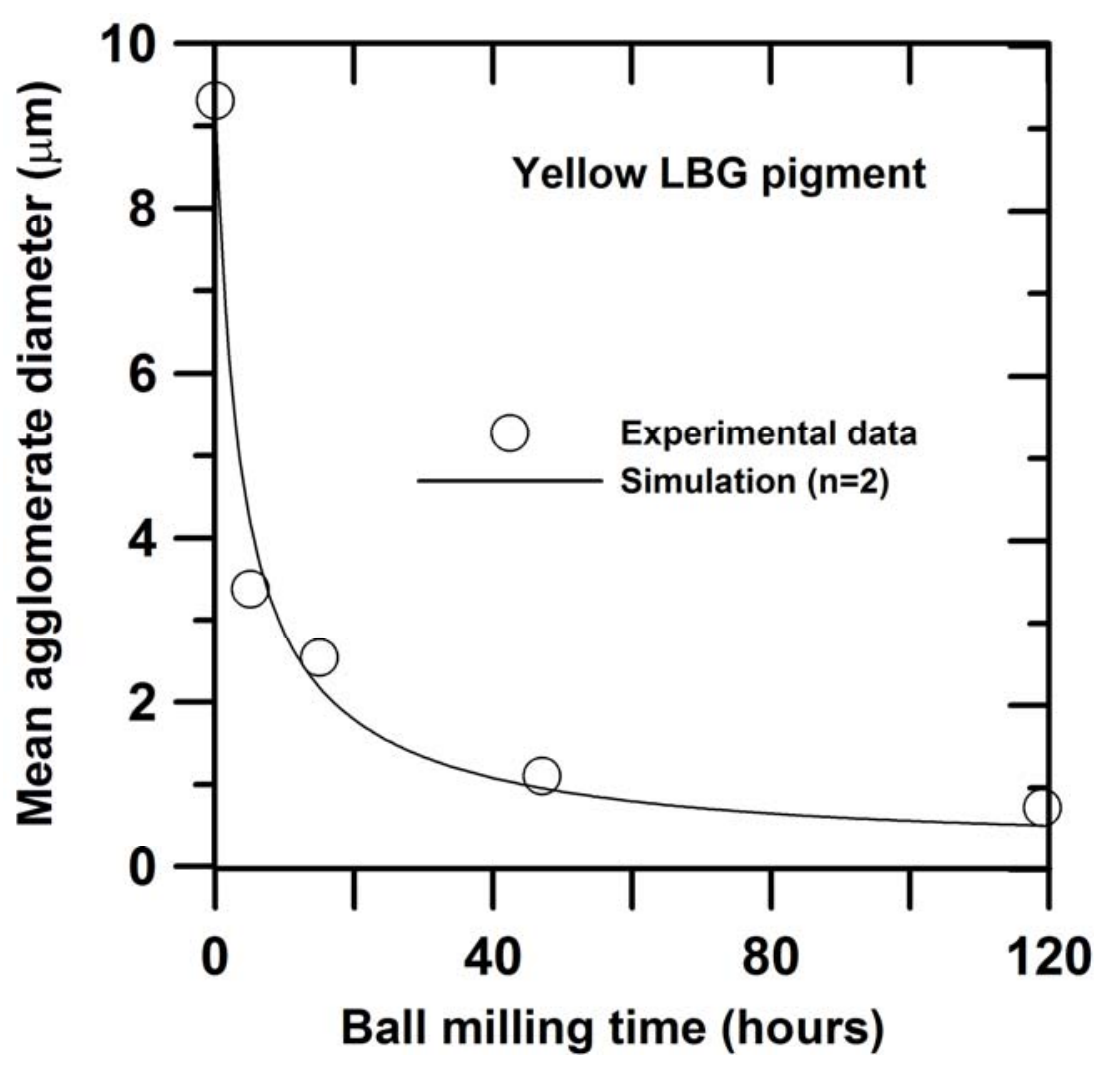

Fig. 8 Volume-moment mean diameter, D[4,3], as a function of ball milling time for Pigment Yellow LBG pigment. The dispersion rate constant, $\mathrm{k}_{\mathrm{d}}$, was equal to $3.3 \mathrm{~m}^{-1} \cdot \mathrm{s}^{-1}$ in the simulation. Notice that the initial mean agglomerate diameter $(9.3 \mu \mathrm{m})$ is substantially lower than that of the B3L pigment $(21.3 \mu \mathrm{m})$ in Fig. 2. Other parameters are $\mathrm{C}_{\mathrm{P}}=210 \mathrm{~kg} / \mathrm{m}^{3}$, $\rho_{\text {pigment }}=1500 \mathrm{~kg} / \mathrm{m}^{3}, \varepsilon_{\mathrm{A}}=0.20, \alpha=0.5$ and $\mathrm{d}_{\mathrm{p}, \min }=0.1 \mu \mathrm{m}$. 


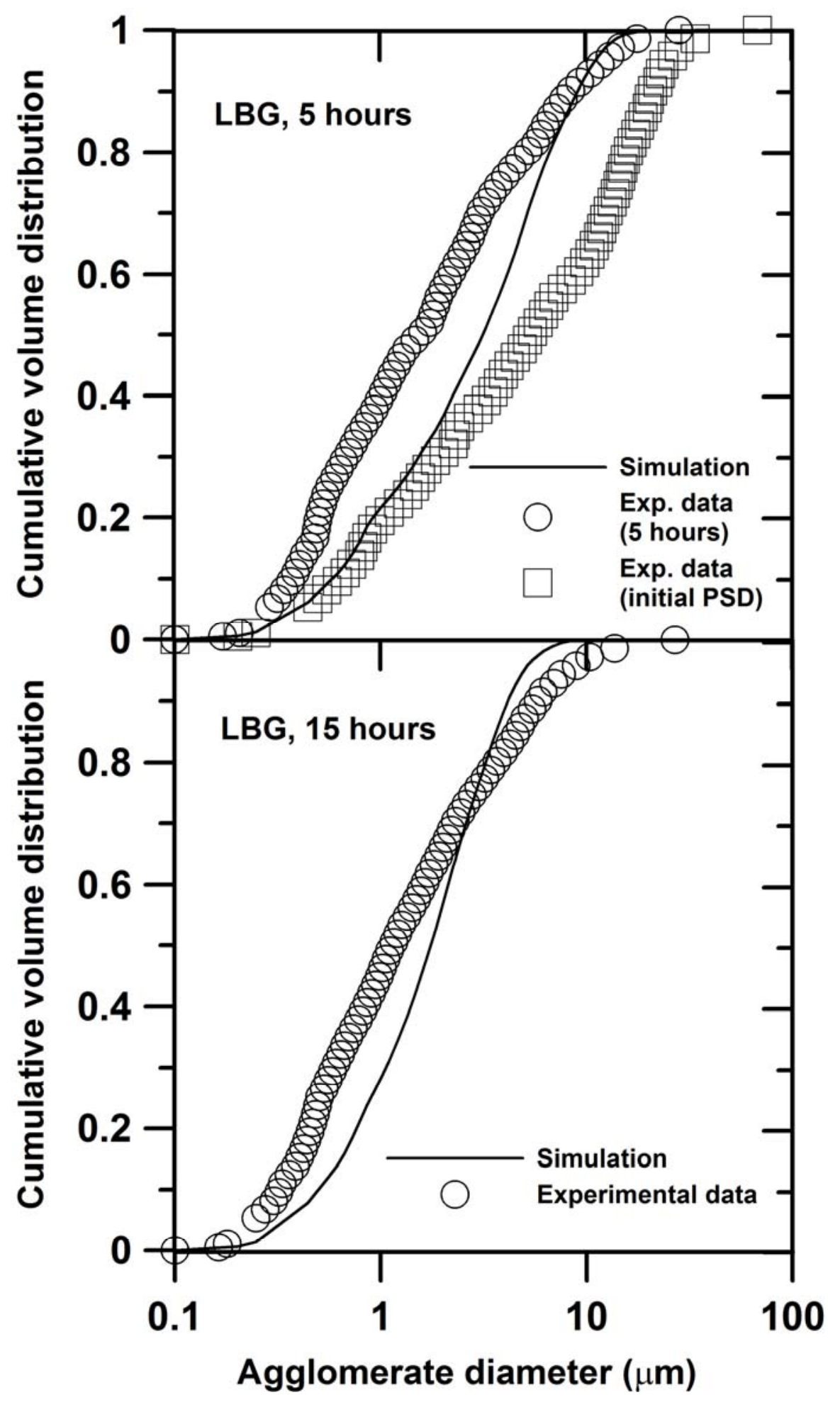

Fig. 9 Comparison of simulations and experimental data for two values of dispersion time (5 and 15 hours) in a ball mill for the LBG pigment. In both simulations shown, $n=2$. In the top plot, also the initial PSD, which serves as an input to simulations, is shown. The dispersion rate constant, $\mathrm{k}_{\mathrm{d}}$, was equal to $3.3 \mathrm{~m}^{-1} \cdot \mathrm{s}^{-1}$ in the simulations. Other parameters as in Fig. 8. 


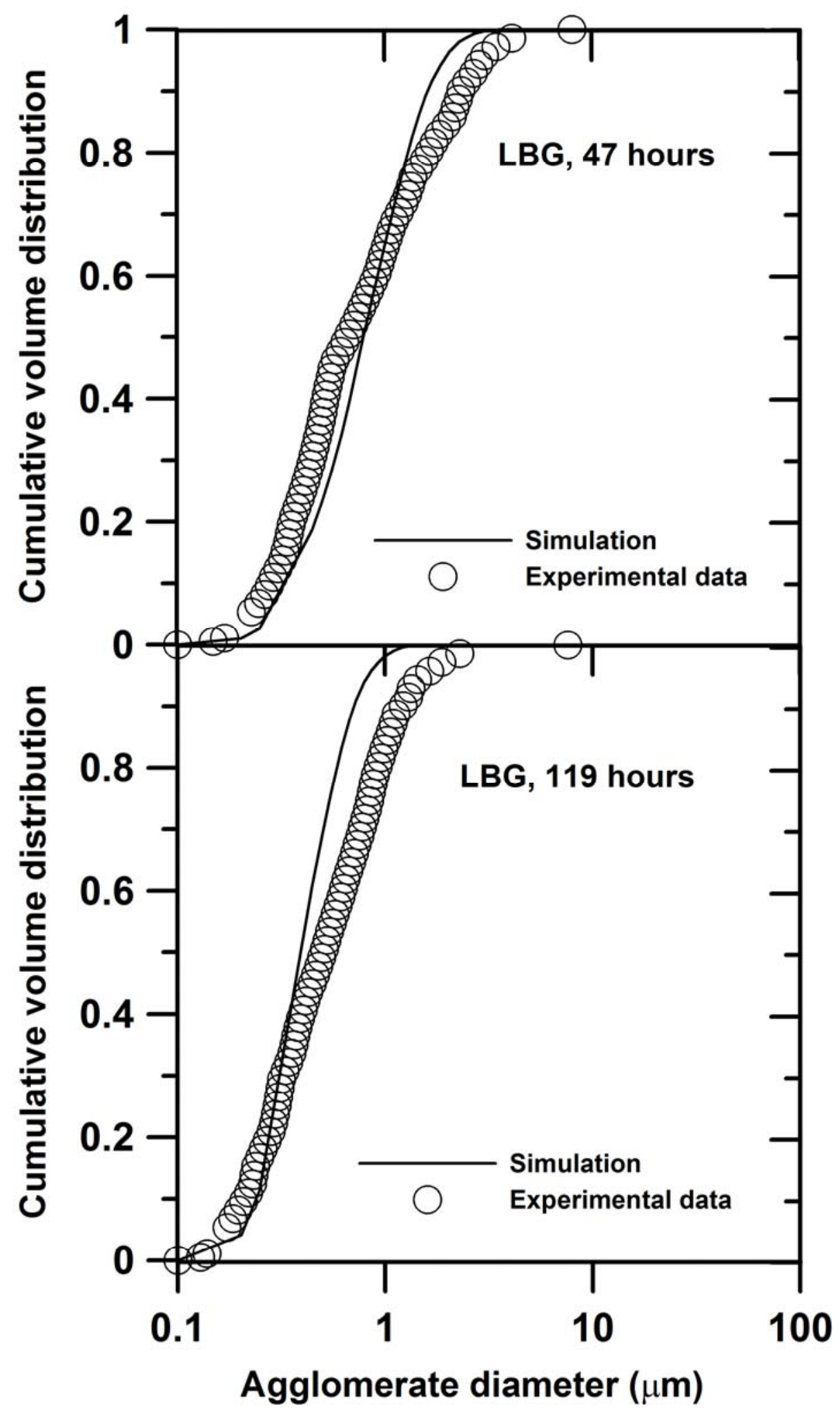

Fig. 10 Comparison of simulations and experimental data for two values of dispersion time (47 and 119 hours) in a ball mill for LBG pigment. In both simulations shown, $n=2$. The dispersion rate constant, $\mathrm{k}_{\mathrm{d}}$, was equal to $3.3 \mathrm{~m}^{-1} \cdot \mathrm{s}^{-1}$ in the simulations. Other parameters as in Fig. 8. 


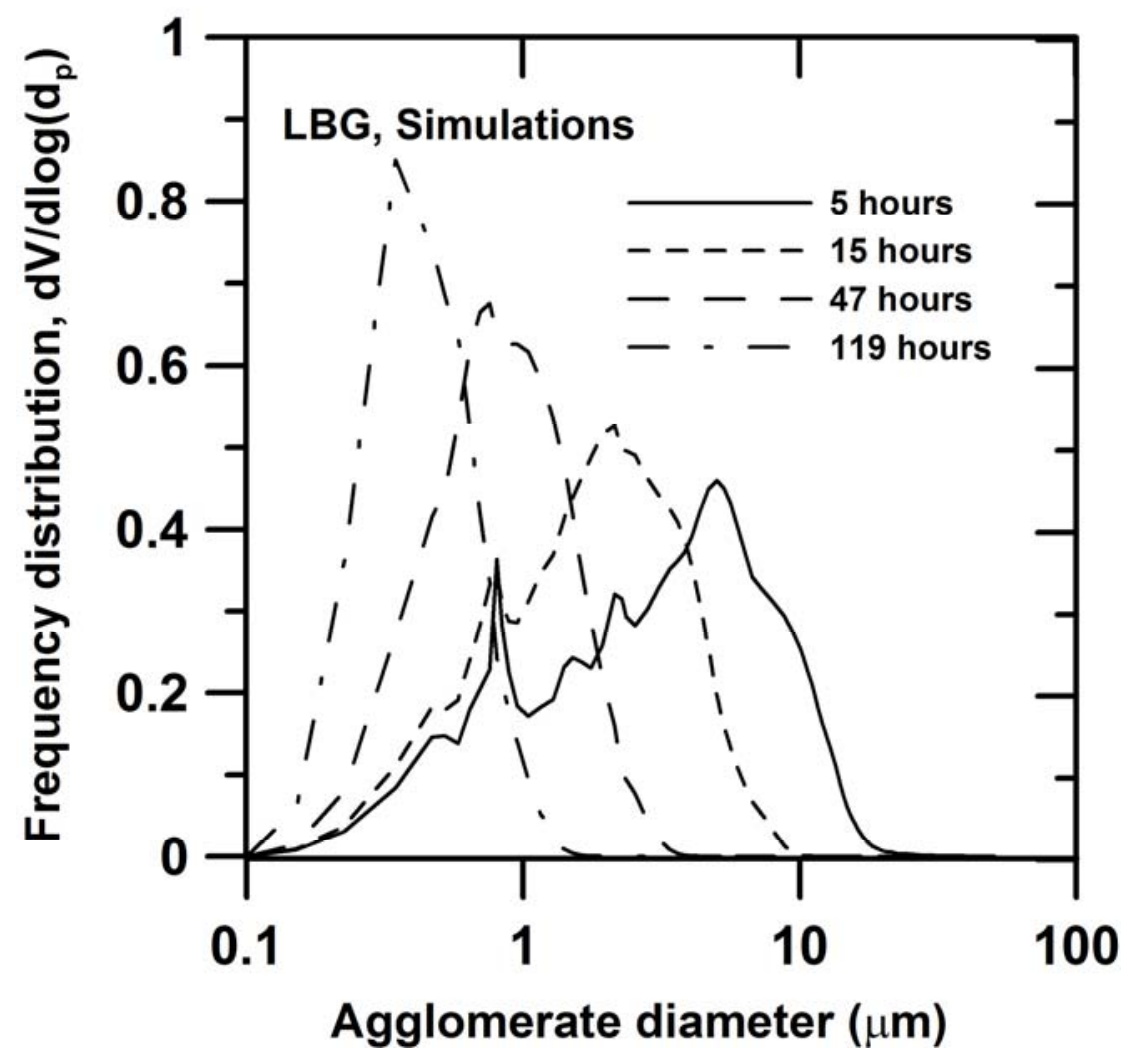

Fig. 11 Simulated frequency distributions for Yellow LBG pigment for four values of time. In all simulations shown, $\mathrm{n}=2$ and the dispersion rate constant, $\mathrm{k}_{\mathrm{d}}$, was equal to $3.3 \mathrm{~m}^{-1} \cdot \mathrm{s}^{-1}$ (corresponding to the simulations in Fig. 9 and 10). The initial distribution $(\mathrm{t}=0)$ is not shown because of "noisy" appearance. Other parameters as in Fig. 8. The area under each of the curves is equal to unity.

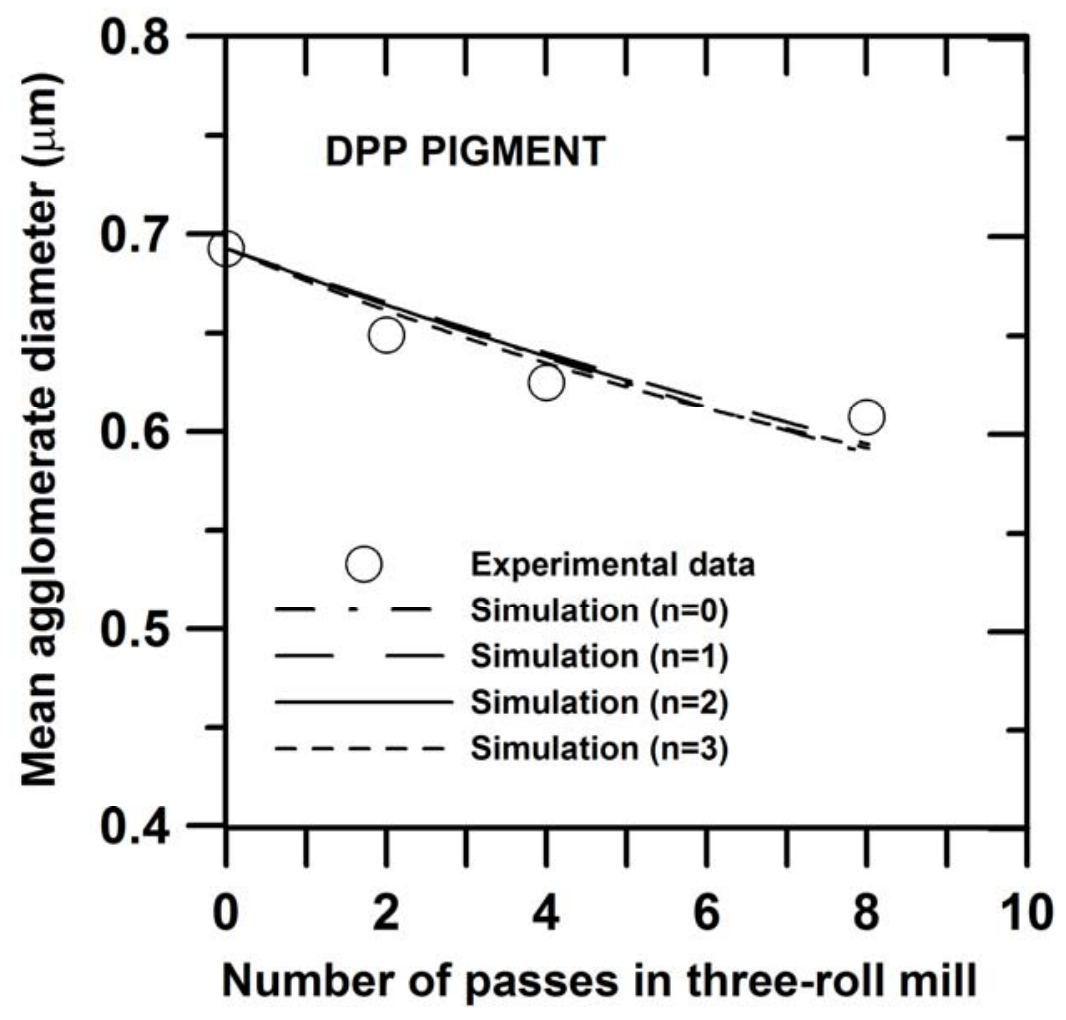


Fig. 12 Volume-moment mean diameter, D[4,3], as a function of three-roll mill time for Pigment Red DPP (passes in the three-roll mill are simulated as dispersion time as discussed in the main text). The values of $\mathrm{k}_{\mathrm{d}}$ used are: $4.62 \cdot 10^{-12} \mathrm{~m} \cdot \mathrm{s}^{-1}(\mathrm{n}=0), 6.27 \cdot 10^{-6} \mathrm{~s}^{-1}(\mathrm{n}=1)$, $8.25 \mathrm{~m}^{-1} \cdot \mathrm{s}^{-1}(\mathrm{n}=2), 9.93 \cdot 10^{6} \mathrm{~m}^{-2} \cdot \mathrm{s}^{-1}(\mathrm{n}=3)$. Other parameters are $C_{P}=210 \mathrm{~kg} / \mathrm{m}^{3}, \rho_{\text {pigment }}=1500$ $\mathrm{kg} / \mathrm{m}^{3}, \varepsilon_{\mathrm{A}}=0.20, \alpha=0.5$ and $\mathrm{d}_{\mathrm{p}, \min }=0.28 \mu \mathrm{m}$. 


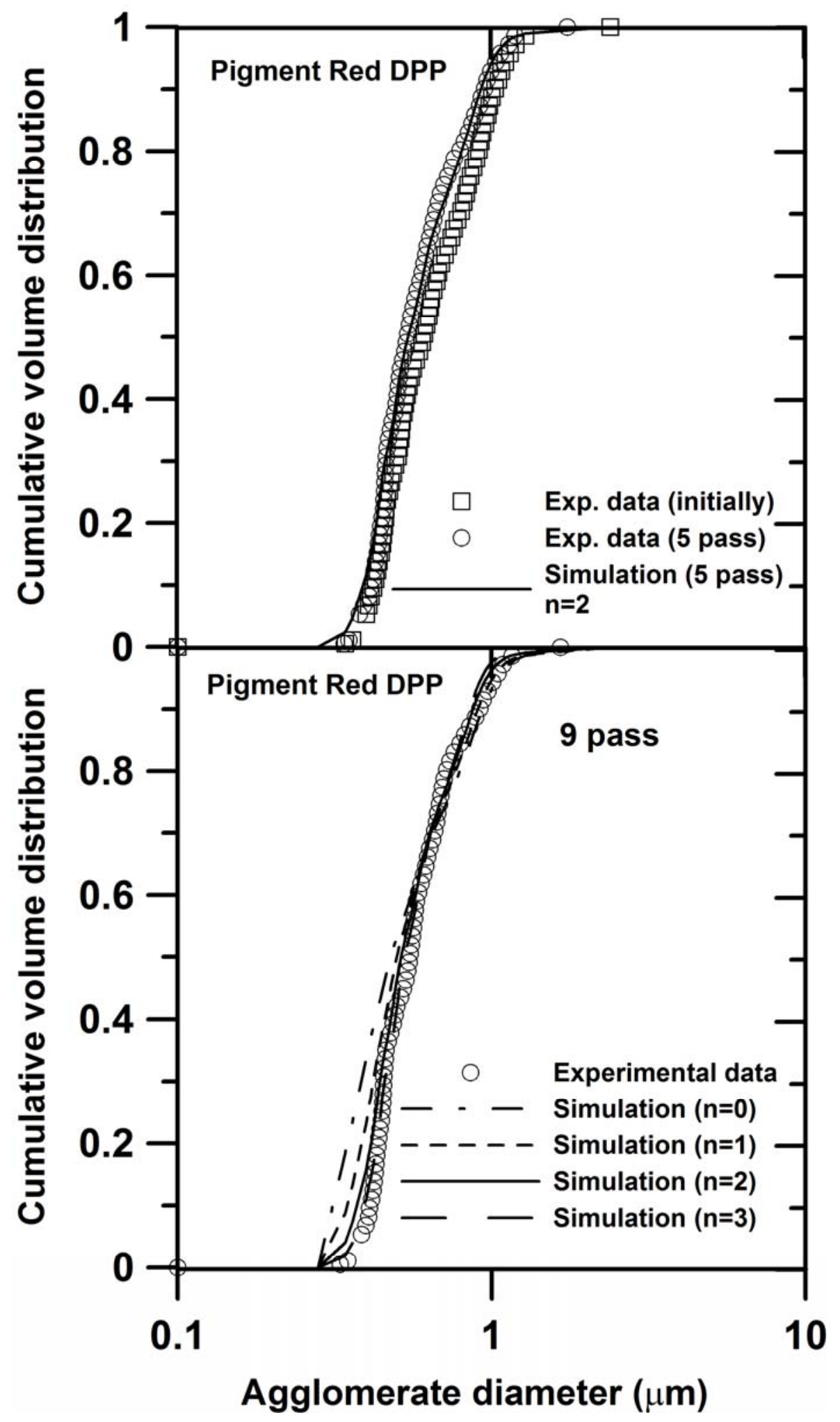

Fig. 13 Comparison of simulations and experimental data for two values of dispersion time (corresponding to 5 and 9 passes in three-roll mill, respectively) for Pigment Red DPP pigment. In the top plot, also the initial PSD, which serves as an input to simulations, is shown. The values of $k_{d}$ used are the same as in Fig. 12. Other parameters as in Fig. 12. 